\title{
Early Identification of Cardiovascular Risk Factors in Adolescents and Follow-Up Intervention Strategies
}

\author{
Heather Lee Kilty and Dawn Prentice \\ Brock University, Nursing Department, Faculty of Applied Health Sciences,
}

Canada

\section{Introduction}

This chapter will explore the strong case being made world-wide for the development and implementation of well designed research and intervention approaches with adolescents to help stem the tide of rising cardiovascular risk factors, and thus to reduce cardiovascular disease in adulthood. It is well established that atherosclerosis begins in childhood and adolescence and that cardiovascular risk in early years can be tracked into adulthood cardiovascular disease (CVD) (Berenson et al., 2010; McCrindle et al., 2010; McCusker, et al., 2004; Yoshinga et al., 2008) .

Research into adolescent cardiovascular (CV) risk factors provides evidence that the development of possible large-scale interventions may hold great promise if conducted before family history repeats itself and before lifestyle choices are entrenched. The more research guides us to identify risk factors and how to measure them accurately, the clearer the path we can follow to identify those adolescents at risk and engage them in reducing risks earlier. It is the hope of the authors that the information presented will serve as a resource to those researchers who provide valuable data and evidence to shape policies and programs to reduce $\mathrm{CV}$ risk. The information is also intended for clinicians who work directly with adolescents in the assessment and management of cardiovascular risk, as well as health educators who engage in primary, secondary and tertiary health promotion.

This chapter is dedicated to exploring aspects of adolescent heart health and risk factors:

1. Research on the prevalence, incidence and concurrence of cardiovascular disease risk factors in adolescents.

2. Research on associations and connections between adolescent $\mathrm{CV}$ risk factors, adult risk factors and the development of CVD.

3. Research methods and instruments used to study, screen, measure and test for cardiovascular risk factors in adolescents at the population health level and at the individual program research level.

4. Current approaches to adolescent heart health awareness, health promotion, screening, prevention, risk reduction, education, referral and treatment.

Examples of adolescent cardiovascular research studies, initiatives and projects in parts of the world and their results or evaluations will be described. Recommendations for 
researchers, health promotion educators, parents and treatment health practitioners working with adolescents on cardiovascular prevention and reduction will be presented. A suggested comprehensive model of cardiovascular adolescent heart health screening, education, consultation and treatment will be presented.

Adolescence is a particular stage in the lifespan that is characterized as being between childhood and adulthood. While adolescents vary in their experiences world-wide and in their degree of independence, adult responsibility, and access to education, it is a common experience that they begin the tasks of establishing their own identity within the wider culture and society within which they live. Their emerging independence includes beginning to exercise their own choices of food, physical activity or inactivity, smoking behaviours, sexual experiences, and social relationships. They carry out degrees of independence within the context of examples set by diverse parenting models, family histories, cultural contexts and societal influences. In many cultures, the majority of adolescents are still in school and this provides an ideal milieu for cardiovascular research, screening and health promotion. Parental and family influences, peers, educators and media all play a role in shaping adolescent health beliefs and lifestyle behaviours that are often carried into adulthood.

\section{The status of cardiovascular disease and the need for earlier research and prevention}

\subsection{Cardiovascular disease: An area of needed research and intervention in the world}

Cardiovascular diseases are a major cause of morbidity and premature mortality in men and women in the industrialized world and many developing countries (Hayman et al., 2004). The WHO (2009) indicates the leading global risks for mortality in the world are high blood pressure (13\% of global deaths), tobacco use $(9 \%)$, high blood glucose $(6 \%)$, physical inactivity $(6 \%)$ and overweight or obesity. These risks are responsible for raising the risk of chronic diseases such as heart disease and cancers. The WHO conference (2009) on a "second wave" epidemic of cardiovascular disease connected with arterial sclerosis, predicted that by the year 2020, cardiovascular diseases will be the leading cause of death in the entire world (Chmiel-Polec, \& Cybulska, 2008).

Heart attacks and coronary heart disease (CHD) are primarily caused by atherosclerosis, where a narrowing and hardening of the arteries result from an accumulation of fat and cholesterol deposits called plaque. This narrowing, or blockage of the arteries stops the supply of blood to the heart and can cause a heart attack, heart failure or even cardiac arrest. "Atherosclerosis also occurs in other blood vessels, such as the carotid artery, which carries blood to the brain, or the arteries that provide blood to the legs, and can lead to similar problems. Significant atheroslerosis in the arteries supplying the brain may cause transient ischemic attacks (TIAs) or strokes, while peripheral arterial blood vessel disease, with intermittent claudication (pain on walking or similar activity) occurs when there is a significant atherosclerosis in the arteries in the legs" (Wong, 2000, p. 23).

Heart disease, which encompasses coronary heart disease and stroke, is estimated to cause one third of all deaths world-wide. Cardiovascular disease (CVD) is estimated to be the leading cause of death and loss of disability-adjusted life years (Yusuf et al., 2004). Although age-adjusted cardiovascular death rates have declined in several developed countries in the 
past decades, rates of CVD have risen greatly in the low-income and middle-income countries. Yusuf et al., (2001) outlined the global burden of cardiovascular diseases. These researchers from Canada and India describe the epidemiological transition in the world from the major causes of death from a predominance of infectious diseases and nutritional deficiencies to those classified as degenerative diseases such as CVD. Although many cardiovascular diseases can be treated or prevented, an estimated millions of people die worldwide each year.

Atherosclerotic cardiovascular disease (CVD) is described as a multi-factorial condition reflecting a lifelong pathological process that begins in childhood (Stary, 1989). Chronic disease and illness are commonly caused by exposure to risk factors many years prior to the onset of the condition. Dietary/ nutritional intake, consumption of alcohol and other substances, smoking, and inactivity are all behaviour patterns established during adolescence and have been linked to obesity and a number of illnesses that develop later in life (Hennekens \& Bering (1987).

Yusef et al. (2004) make the case for a global strategy of cardiovascular research for the prevention of CVD: "Effective prevention needs a global strategy based on knowledge of the importance of risk factors for cardiovascular disease in different geographical regions and amongst various ethnic groups" (p. 937). The bulk of the research to date has been on European and North American, populations, but studies related to CVD in the general adult population and risk factors that begin in childhood and adolescence are adding to the cumulative body of research, theory and knowledge from many countries around the world. "Although more than $80 \%$ of the global burden of cardio-vascular disease occurs in lowincome and middle-income countries, knowledge of the importance of risk factors is largely derived from developed countries. Therefore, the effect of such factors on risk of coronary heart disease in most regions of the world is unknown" (Yusuf et al, 2004, p. 937).

Yusuf et al. (2004) conducted a standardized case-control study of myocardial infarction in 52 countries, involving 262 centers representing every inhabited continent. This study was part of INTERHEART, a large international, standardized coronary heart disease casecontrol study designed as an initial step to assess the importance of risk factors for CVD. The study enrolled 15,152 cases and 14,820 controls. Nine easily measured and potentially modifiable risk factors accounted for an overwhelmingly large (over 90\%) proportion of the risk of an initial acute myocardial infarction (MI). The research reported on the relationship of smoking, history of hypertension or diabetes, waist/hip ratio, dietary patterns, physical activity, consumption of alcohol, blood apoliproteins (Apoli), and psychosocial factors related to MI. The presence of multiple risk factors, hypertension and diabetes were found to increase the odds for acute MI. Obesity rates were found to vary in different parts of the world.

Each country is struggling to research the impact of CVD on their population, as well as the resultant impact on health services and finances. In Canada, as in many nations, CVD is the major cause of death, disability, and illness that has a significant impact on the health care system, accounting for more discharges from hospital than any other major disease group. The costs of hospitalization, medical care, drugs, and research related to CVD present a substantial cost burden to most countries (Yusef et al., 2004). 
The Canadian Heart and Stroke Foundation's Annual Report (2010) warns that young Canadian adults are increasingly at risk for heart disease: And that "a perfect storm of risk factors and demographic changes are converging to create an unprecedented burden on Canada's fragmented system of cardiovascular care, and no Canadian young or old will be left unaffected" (p. 2). The report points out that "Young people are beginning their adult lives with multiple risk factors for heart disease." The report states that people used to think that heart disease and stroke, type 2 diabetes and high blood pressure were 'diseases of aging.' The report sounds a warning that these increases (in overweight and obesity, high blood pressure and diabetes) "will translate into an explosion of heart disease in the next generation" (p.2).

According to the Canadian Community Health Survey data 2007/2008, many heart health risk factors are already present in 20 to 34 year olds with health behaviours that began earlier in childhood and adolescence. Of the participants sampled, $47.0 \%$ were physically inactive, $40.5 \%$ were overweight or obese; $29.0 \%$ were smokers; $2.5 \%$ had high blood pressure and; $1 \%$ had diabetes. By ages $45-64$, those numbers are: $52.8 \%$ reporting physical inactivity; $58.2 \%$ were overweight or obese; $23.1 \%$ were smokers; $22.9 \%$ had high blood pressure and; $8.3 \%$ had diabetes. For women and the aboriginal population, the numbers are even greater. CVD is the number one cause of death and disease in Canadian women.

While associations are being determined in the research between and among identified risk factors, the prevalence of each respective factor may vary in different populations. This phenomenon is referred to as population attributable risk (PAR) (Yusuf et al.2004). For example, lipids have not been found to be associated with heart disease disorders in South Asians; increases in blood pressure might be more important in Chinese people; serum cholesterol might be lower in the Chinese population; and diabetes and high blood pressure may be more prevalent in the North American Aboriginal population. The differences found in risk levels may be a result of cultural health habits, or they could be attributed to differences in the research design, analysis, information obtained and sample sizes. Crosscultural research for adolescents and adult populations should examine their findings carefully in regard to making inferences about risk factors in varying populations and cultural contexts.

The WHO (2009) identified eight risk factors that account for $61 \%$ of cardiovascular deaths in the world: high blood pressure, high body mass index, high cholesterol, high blood glucose, low fruit and vegetable intake, alcohol use, and physical inactivity. Combined, these same risks factors "account for three quarters of ischaemic heart disease: the leading cause of death world-wide" (p. v). Many of these risk factors begin in childhood and adolescence.

\section{Adolescence as an important target stage for research on the identification and modification of cardiac risk factors}

\subsection{The case for earlier intervention and the search for where to begin}

Adolescent years are marked by many physical, social and emotional changes that take place within the cultural and political social and economic contexts within which adolescents begin to transition into adulthood and more habitual behaviours (Mathers, 1998). Nutritional intake, physical activity or inactivity and smoking attitudes and 
behaviours begin in childhood. These patterns get more established in adolescence and can transition into entrenched lifestyle habits in adulthood. Research on adolescents is valuable at this stage of lifespan development to identify those risk factors and their prevalence, so that individuals and societies can make decisions about where to put their health promotion and risk reduction efforts, based on the evidence.

Erikson (1950, 1977) described the lifespan developmental stages and the struggles, strengths and tasks of each period of development. He called the adolescent period of puberty and teenage times from age 12 to 18 years of age as a time of identity vs role confusion. He stated that up until this time, development depended mostly on what is done to us, whereas from that point on, development depended more on what the individual does. It is a time to find an identity separate from the family of origin, to struggle with social interactions, and to grapple with moral issues.

Many CV risk factors are adopted by adolescents without awareness of their present and longterm impacts on health or the potential development of heart disease. Adolescents are still shaping, re-shaping and creating their identities. Most writers acknowledge that heart health education and screening can and should be initiated in childhood before adolescence begins. However, adolescence is a key point of entry, where risk factors can be made known not only to families, health practitioners, and educators, but to the individual adolescent directly so he or she can be potentially informed, empowered and motivated to make their own changes.

It is generally postulated that CVD, including heart disease and stroke is largely preventable (apart from age and heredity) through adopting a healthy lifestyle that includes no smoking, healthy food choices, physical activity, the management of stress and the maintenance of healthy weight (Health Canada, 2011). Preventive care is appropriate to control blood pressure, blood cholesterol and other lipids. Flouris et al. (2007), in their study of CV disease risk factors in Ontario adolescents state that: "Within the limitations of the study adolescents, especially those with low cardiovascular fitness appear to be at an increased risk for developing CVD at a later life stage. These findings highlight the necessity of placing adolescents in the forefront of preventive cardiovascular disease programs and should receive particular attention by healthcare authorities in order to minimize future CVD attributed mortality rates" (p. 523). They caution that risk and gender findings could also be influenced by pubertal influences.

Adolescents of many nations are dealing with additional health threatening conditions of famine, war, and natural disasters that further complicate the process of moving through adolescence to adulthood. Regardless, adolescents of all cultures are often in that childhood to adulthood, in between stage where the health behaviours of childhood and family teachings shape some of their health behaviours and choices mixed along with some emerging independent choices of young adulthood. Eating, physical activity, smoking and substance using behaviours of youth have long been areas of study that have relevance to future heart health outcomes. Genetic, aging, cultural, societal, peer and family trends also have an impact on heart risks and CVD.

In many populations, adolescents tend to have a lower incidence and prevalence of psychosocial and medical disorders and are often the healthiest subgroup of the general population (Mathers, 1998). Despite this good news, the general health status of adolescents has not improved over the last 30 years (Stanton et al., 2000). The study of adolescent health 
and early established healthy and unhealthy behaviours is warranted if we wish to understand childhood and adolescent influences and intervene earlier in the development of CVD at an opportune time when the adolescent is beginning to make their own choices.

Adolescence is a life stage where the individual is still influenced by the family, but beginning to make independent choices in many areas to establish their own lifestyle habits, behaviours, values and beliefs. That in-between place makes working with adolescents on health promotion a very promising and challenging endeavour. In the case of the adolescent who has smoking parents, a physically inactive household and poor nutritional intake historically, and he or she begins to exercise, eat well and not smoke - these are positive changes in the right direction. For the adolescent who comes from healthy beginnings and begins to smoke, eat poorly and not exercise, - the choices may have a negative impact on heart health and the development of cardiovascular disease. For certain, the adolescent period is a period of influences from family, peers, education and media mixed with opportunities for change, for better or worse in regards to health.

\section{Risk factors and research particularly related to adolescents}

\subsection{Categories of risk factors}

A cardiovascular risk factor is a condition that is associated with an increased risk of developing cardiovascular disease. Cardiovascular (CV) risk factors fall into two distinct categories: those that cannot be changed and those that can be modified, treated or controlled (American Heart Association [AHA], 2007).

The major risk factors that cannot be changed are:

- Increasing age ... The risk of cardiovascular events increases as we get older. Many epidemiological studies have indicated that age is one of the strongest predictors of disease. Over half of those even up to $83 \%$ of people who die of coronary heart disease are 65 and older. At older ages, women who have heart attacks are more likely to die from them within a few weeks.

- Gender ... Men have a greater risk of heart attack than women and they have attacks earlier in life. Even after menopause, when women's death rates from heart disease increase, they are still not as great as the rates for men. We are not certain if male hormones (androgens) increase risks or female hormones (estrogens) protect against atherosclerosis. This gender difference could also be attributed to past smoking patterns where men smoked more than women. These patterns are changing and women could be losing their advantage in this area as smoking in women rises.

- Heredity (including race) ... Children who have parents or siblings who have heart disease are more likely to develop it themselves. They have a significantly greater likelihood of having a heart attack or stroke. Familial hypercholesterolemia and its accompanying biological defects are well characterized as a known risk for CVD. Individuals who have a family history of heart disease that occurred early (before 55) especially should be more vigilant and adopt modifiable healthy behaviours. People with a strong family history of heart disease often have one or more risk factors. African Americans have been found to have more severe high blood pressure than Caucasians, and a higher risk of heart disease. Heart disease risk is higher in the U.S. among 
Mexican Americans, Native Americans, native Hawaiians and some Asian Americans; this is partially due to higher rates of obesity and diabetes (Adapted from AHA, 2007).

The major modifiable predisposing risk factors that can be prevented, treated or controlled:

- Risk behaviours ... tobacco smoking, physical inactivity, and poor eating habits

- Risk signs ... high blood cholesterol and related lipids, and high blood pressure,

- Resulting conditions ... obesity and overweightness, and the development of diabetes mellitus.

Other risk factors that have been identified with heart disease in the research are: individual stress response, depression, drinking too much alcohol, sleep patterns, and socioeconomic status (SES).

Simply having a risk factor associated with heart failure does not mean that an individual will develop heart failure. Many of the factors are controllable and involve healthy heart lifestyle awareness and changes. Black, (in Wong et al. 2000) states that "The association is a statistical one, and so the fact that a particular person has a particular factor merely increases the probability of developing a certain type of cardiovascular disease, it does not mean that he or she is certain to develop heart or blood vessel disease. Conversely, the fact that an individual does not have a particular cardiovascular risk factor (or for that matter, any known cardiovascular risk factors) does not guarantee protection against heart disease" (p. 33).

Black suggests there are also certain protective factors that we need to understand more about and how they impact positively on cardiovascular disease. He includes the following in his list of identified protective factors: HDL cholesterol, exercise, estrogen, and the moderate intake of alcohol.

Example research studies related to the prevalence, co-occurrence or clustered presence of primary risk factors in adolescents will be discussed later in the chapter (smoking, blood pressure, cholesterol, BMI, physical activity, nutrition and obesity). Additional risk factors are also present in the adolescent stage that influence overall health and heart health that include: substance abuse, socio-economic status (SES), suicide, depression, drinking and driving, and sexually transmitted diseases. Several studies have explored the presence of individual risk factors and the presence of multiple factors and the associations between them. Several risk factors will be reviewed here, along with sample studies and approaches used to study and measure that particular risk factor in adolescents.

\subsection{Research on the co-occurrence (clustering) of cardiovascular risk factors}

It is well known that an increase or decrease in the number of CV risk factors is strongly associated with the improvement or worsening of individual risk factors (Nakumura et al., 2001; Yoshinaga et al., 2008; Yoshinaga et al., 2010).

Yoshinaga et al. (2010) stated that little is known about the impact of having one CV risk factor on the other levels of other $\mathrm{CV}$ factors in the general adolescent population. The researchers hypothesized that when adolescents have one risk factor, the level of the other CV risk factors worsens simultaneously. A sample of 1,257 healthy adolescents (549 males and 708 females) aged 15-18 years were assessed using: risk factors of abdominal obesity, 
hypertension, raised triglyceride levels, decreased HDL cholesterol levels and hyperglycemia. Homeostatic assessment of insulin resistance (HOMA-IR) was used as a surrogate marker of insulin resistance. The levels of all CV risk factors and HOMA-IR significantly and simultaneously worsened when adolescents had one risk factor, in both genders. Having one risk factor indicated the development of other risk factors in adolescents, especially the development of abdominal obesity in male subjects was found to have a harmful effect on other $\mathrm{CV}$ risk factors. They concluded that it is important to determine the presence or absence of $\mathrm{CV}$ risk factors before and/or during adolescence, because having one $\mathrm{CV}$ risk factor can indicate the start of an accumulation of $\mathrm{CV}$ risk factors in the general adolescent population.

Lobelo et al., (2010) in a cross-sectional study of 1,247 youth 12-19 years of age in the U.S. using data from the 1999-2002 National Health and Nutrition Examination Survey (NHANES), examined the association between cardiovascular fitness (CRF) distribution and CVD risk measured as continuous scores for individual and clustered CVD risk factors to explore the potential effect modification of the association exerted by weight status among adolescents. They used a treadmill test and categorized age and sex specific quintiles and researched five established risk factors with an adiposity index that included the sum of triceps and subscapular skinfolds; the homeostatic model assessment of insulin resistance; systolic blood pressure; triglycerides and total cholesterol/high density lipoprotein cholesterol, standardized for age and gender A clustered score was calculated as their average. The mean clustered risk score decreased with increasing CRF in both males and females. Most of the clustered CVD risk was found among adolescents within the lowest quintile of CRF distribution.

A cross-sectional study was conducted by McCrindle et al. (2010) with 20,719 beginning high school students in the Niagara Region of Ontario, Canada with data reported over a seven year period. The aim of a study conducted from 2002 to 2008 was to examine population trends of increasing cardiovascular risk factors in 14 to 15 year old students participating in the Niagara Schools Healthy Heart Program (NSHHP). The program provides identification of cardiovascular risk factors for teens enrolled in a grade nine physical education program in secondary schools in Niagara.

Through an assessment, adolescents were identified and referred to their family physician for further follow-up. The physical assessment measures included height and weight, capillary sample for non-fasting total cholesterol level, and blood pressure measurement. A family cardiovascular risk history assessment questionnaire was completed that asked about first degree family members who had hyperlipidemia, hypertension or diabetes. A lifestyle questionnaire completed by the students assessed the amount of physical activity over a week, amount of television watched, the amount of time spent on videogames and the amount of time spent on the computer. A self-reported nutritional questionnaire asked students about consumption of fruits and vegetables, fast-food intake, amount of soda and caffeine intake and whether or not the students ate breakfast. The McCrindle et al., (2010) study used the student's electoral district as a substitute marker to determine the socioeconomic status.

Almost $20 \%$ of the students had one cardiovascular disease risk factor. The investigators reported that during the study period, the percentage of obese teens' body mass index (BMI) increased significantly, and non-fasting total high cholesterol levels also significantly 
increased. Additionally, the percentage of students with borderline high total cholesterol increased. The authors reported that "family history, low levels of physical activity, sedentary behaviours, poor nutrition and lower socioeconomic status were all independently and negatively associated with all aspects of cardiovascular risk" (p. 837). Findings from this study supported the need for continued surveillance to provide early identification and follow-up of students with cardiovascular risk factors.

Two sub-studies were conducted as part of the Niagara Schools Healthy Heart Program. (NSHHP) Data for the years 2002, 2003 and 2005 were analyzed by Prentice, Kilty, Stearne and Dobbin (2006). Over 10, 000 students from thirty schools participated in the NSSHP during that time frame. Trends indicated that more female students reported smoking; more male students reported being active for 30 minutes per days as compared to female students; and the amount of self-reported television watching and video game use decreased over the three years. The referrals of those identified with risk factors (higher blood pressure/ or cholesterol) to family health practitioners remained fairly constant at almost $5 \%$. The researchers concluded that collaborative programs such as the NSHHP are challenging to implement within a school system, yet early assessment, education and identification of risk factors are essential in cardiovascular disease prevention.

A previous sub-study was conducted by Prentice, Kilty, Stearne and Dobbin (2008) with 3,639 grade nine students in 30 secondary schools in the Niagara Region. The study was part of an evaluation of the Niagara Schools Healthy Heart Program (NSHHP), a primary prevention program that was in effect since 1987. The Program has multiple components: a one hour educational session on heart health, CPR training, a self- assessment component which includes a self-rated questionnaire on dietary intake, caffeine intake, level of physical activity and smoking. A questionnaire on family history of cardiovascular disease is sent home to be completed in conjunction with parents. Registered public health school nurses measured height, weight to calculate the Body Mass Index (BMI). Blood pressure and nonfasting total cholesterol screening were also tested. If any abnormalities are detected, the students were referred to their primary health care provider for follow-up. Data were analyzed for the school year 2006. The researchers reported that $14 \%$ of the participants had one or more cardiovascular risk factors. The most common risk factor was BMI $(13.7 \%)$. Of the sample, $5.0 \%$ had an elevated random total cholesterol $>5.2(6.2 \%$ females and $3.8 \%$ males); and $5.8 \%$ of the sample had a blood pressure systolic reading greater than $135 \mathrm{mmHg}$ and a diastolic reading of $85 \mathrm{mmHg}$ or greater. In terms of gender differences, female students reported smoking more and had higher cholesterol levels. Male students were more likely to have an increased BMI. There were no gender differences in the prevalence rates of elevated blood pressure. The findings suggest that cardiovascular risks are already present in adolescents. It was recommended that this group be followed up in the future and retested in grade twelve and that an additional focus should be on earlier prevention program initiatives with younger children.

Shatoor et al. (2010) conducted a cross-sectional study in Saudi Arabia on a stratified sample of 1,249 adolescent secondary school boys. More than $25 \%$ did not practice regular exercise and there was a high parental history of hypertension, diabetes and high blood pressure. They called for a national program to prevent cardiovascular risk factors among adolescents. 
Andersen et al. (2003) conducted a study exploring biological cardiovascular risk factor clusters in Danish children and adolescents as part of the larger European Youth Heart Study. The aim of the study was to determine whether the number of participants with multiple coronary heart disease (CHD) risk factors exceeded the number expected from random distribution. The cross-sectional study included 1,020 randomly selected boys and girls, aged 9 and 15 years. The risk factors studied were: total cholesterol, HDL cholesterol, triglyceride, serum insulin, and blood pressure. Physical fitness was assessed from a maximal cycle test and body fat sum of four skinfolds taken. More participants than expected had four or five CHD risk factors. Four risk factors were found in 3.03 times as many participants as expected from random distribution and five risk factors were found in 8.70 times as many participants as expected. Fifty (5.4\%) had 4 or 5 risk factors and in these individuals, physical fitness was 1.2 standard deviation lower and BMI was 1.6 SD higher than the mean values for the population. A clustering of risk factors was found for children and adolescents, where when one was present, several factors were also present.

Bouziotas and Koutedakis (2003) examined the prevalence of 14 modifiable CHD risk factors in a sample of 210 provincial Greek children as they progressed from 12 to 14 years of age. It was found that $46.2 \%$ of boys and $49.5 \%$ of girls had three or more risk factors at their $12^{\text {th }}$ year; $42 \%$ boys and $51.1 \%$ girls in their $13^{\text {th }}$ year and; $29.4 \%$ boys and $55 \%$ girls in their $14^{\text {th }}$ year. Males had more physical activity and less body fat; girls had an elevated percentage of body fat, percentage of intake of saturated fat, and total cholesterol. They concluded that a high percentage of Greek boys and girls exhibit three or more modifiable CHD risk factors and as they progress from 12-13 years of age, gender differences start to emerge in the prevalence and development of CHD risk factors.

\subsection{Research on the main cardiovascular risk factors for adolescents and their measurement}

For each risk factor included in this review there will be:

- An introduction describing available information on that risk factor;

- Sample research studies on adolescent prevalence and data related to that risk factor;

- Measurement standards and approaches;

- World Health Organization results of the School-Aged Study conducted in regions around the world (2008) and;

- $\quad$ Suggested advice for this risk factor.

\subsubsection{Smoking as a CV risk factor in adolescents}

Introduction ...

Cigarette smoking among adults primarily starts in adolescence and continues to be a major public health problem world-wide. Tobacco use is considered the number one individually preventable and modifiable cause of cancer and cardiovascular disease (Elders, 1994; United States of America (USA) Dept of Health and Human Services in Greenlund et al., 1996).

Known psychosocial risk factors for smoking among adolescents include the presence of other smokers in the family unit, smoking among friends, peer acceptance of smoking, age 
and socio-economic factors (Wang, Fitzbugh, Westerfield, \& Eddy, 2003; Barber, Bolitho, \& Berrand, 1999; Fied 1994 in Winter, de Guia, Ferrence \& Cohen, 2002).

Sample studies ...

Greenlund et al. (1996) studied trends in cigarette smoking among children in a U.S. southern community from 1976-1994 as part of the Bogalusa Heart Study, which conducted a long-term investigation of cardiovascular disease beginning in childhood with studies up to age 40 years. Smoking trends from 1976-1977 and 1992-1994 were examined to investigate cardiovascular disease risk factors among black and white; male and female adolescents. Age-race-sex specific tests for trends over five survey periods were conducted. In almost every age group, black boys and girls had sharp decreases and were less likely to be a current smoker than their white counterparts. These substantial decreases were not observed in white children.

Shields (2005) summarized the results from National Population Health Survey (NPHS) and the Canadian Community Health Survey (CCHS) in 2003 and reported that for those 12 and over $10.5 \%$ were exposed to second hand smoke at home; and $88.9 \%$ were not. According to the CCHS, (2003), one in ten (10\%) of those 12-17 years old smoked cigarettes; more than half (50\%) of those smoked daily; boys and girls were almost equally likely to report smoking (10\% of boys and $11 \%$ of girls). The $2007 / 2008$ CCHS reported that $29.0 \%$ of those $20-34$ years smoked; $25.6 \%$ of those $35-44$ years smoked; and $23.1 \%$ of those $45-64$ years smoked.

Winter et al., (2002) examined the relationship between body weight perceptions, weight control behaviours and smoking status among adolescents. Although there is some evidence that smoking affects body weight, the direction of the causality is not clear, and the relationship appears to interact with age. Adult smokers have a lower BMI than non smokers; although the physiological mechanism responsible for this difference is still unclear. In adolescent populations, smokers tend to weigh more than non-smokers. This study used a major Canadian provincial database, the 1997 Ontario Students' Drug Use Survey (OSDUS) to examine the independent effects of body weight perception and both moderate and extreme weight control behaviours on smoking status among both male and female students. A 37\% response rate surveyed a sample of 3,990 public and Catholic school students enrolled in grades 7, 9, 11 and 13 from 168 schools in Ontario, Canada were surveyed. This biannual survey was carried out by the Centre for Addiction and Mental Health (formerly, the Addiction Research Foundation) since 1977. Based on unadjusted analyses, females who believed they were overweight had more than $50 \%$ greater odds of being smokers compared to those who believed themselves to be of average weight or too thin. Weight perceptions were not associated with smoking among males.

\section{SUGGESTED ADVICE REGARDING SMOKING}

Quit smoking

Use effective smoking cessation strategies

\subsubsection{Poor nutrition and eating habits as CV risk factors in adolescents}

Introduction ...

According to the U.S. National High Blood Pressure Education Program Working Group (2004), "Despite the lack of firm evidence about dietary intervention in children, it is 
generally accepted that hypertensive individuals can benefit from a dietary increase in fresh vegetables, fresh fruits, fiber, and nonfat dairy as well as a reduction of sodium" (p. 566).

Eating a healthy breakfast each day has been suggested. Siega-Riz et al. (1998) studied trends in breakfast consumption for children 1-10 years of age and adolescents 11-18 years from 1965-1991 and found a decline in breakfast consumption, especially for 15-18 year olds from $89.7 \%$ to $74.9 \%$ in boys and from $84.4 \%$ to $64.7 \%$ in girls. Results suggested that the decline was because of behavioural changes. They conclude that given the association of obesity with less frequent breakfast consumption, and the rise of obesity in this group, a renewed emphasis on the importance of breakfast is warranted. Smith et al. (2010) explored longitudinal associations with cardiometabolic factors in the childhood determinants of health in a sample of 9-15 year olds in Australia. They found that skipping breakfast over a long period may have detrimental effects on cardiometabolic health and that "Promoting the benefits of eating breakfast could be a simple and important public health message ( $p$. 1316).

\section{Sample studies ...}

In what has been referred to as the Cardiovascular Risk in Young Finns Study (Aatola et al., 2010) a cohort of 1,622 subjects was followed up for 27 years. The baseline data collected in 1980 for 3-18 year olds with lifetime data available since childhood. Arterial adult pulse wave velocity (PWV) was measured in 2007 by a whole-body impedance cardiography device. Vegetable consumption in childhood was found to be inversely associated with adulthood PWV. Vegetable consumption was also an independent predictor of PWV in adulthood. Persistently high consumption of both fruits and vegetables from childhood to adulthood was associated with lower PWV, compared to persistently low consumption. The number of risk factors in childhood was also directly associated with PWV in adulthood. Those findings suggest that lifetime lifestyle risk factors with low consumption of fruits and vegetables in particular are related to arterial stiffness in young adulthood.

Cardiologists and health specialists have long been concerned about dietary fat and added sugars. From 1970 to 2000 in adults, the prevalence of obesity tripled while the intake of energy from fat decreased significantly. During that time, sugar-sweetened beverages increased dramatically. Kavey (2010) reported on the analysis of the data from the National Health and Nutrition Examination Survey (NHANES) from 2007 to 2008. In children and adolescents, an analysis of the 1989-1991 Continuing Survey of Food Intakes by Individuals revealed that 2-18 year olds in the U.S. consumed 6.5\% of their energy from sugarsweetened beverages. From a Reedy and Krebs-Smith's study (2010), an analysis of the recall from children and adolescents revealed a per capita consumption of sugar-sweetened beverages and $100 \%$ fruit juice drinks went up from a mean of $242 \mathrm{kcal} /$ day in the first day to $270 \mathrm{kcal} /$ day in the second day. Combined, they account for $10-15 \%$ of total energy intake. High added sugar consumption in the form of sugar-sweetened beverages is associated with cardiovascular risk factors, both independently and through the development of obesity.

Consumption of added sugars and indicators of cardiovascular disease was studied by Welsh et al. (2010) in the United States. A cross-sectional study of 2,157 adolescents in the National Health and Nutrition Examination Survey (NHANES) from 1999-2004 collected and analyzed dietary data from one 24-hour recall along with sugar content data from the 
U.S. Department of Agriculture MyPyramid Equivalents databases. Measures of CVD risk were estimated by the added sugar consumption levels. Added sugar consumption levels were positively correlated with low density lipoprotein cholesterol levels (mmol/L) which were 1.40 among the lowest consumers and 1.28 among the highest. Added sugars were found to be positively correlated with low intensity lipoproteins. Among the lowest and highest consumers, respectively, low-density lipoproteins were $2.24(\mathrm{mmol} / \mathrm{L})$ and 2.44 and triglycerides were $0.81(\mathrm{mmol} / \mathrm{L})$ and 0.89 . Among those who were overweight or obese, added sugars were positively correlated with the homeostasis assessment model. Researchers concluded that consumption of added sugars among U.S. adolescents is positively associated with multiple measures known to increase cardiovascular disease risk.

World Health Organization (WHO, 2008): Health behavior in school-aged children international report from the 2005/2006 survey in 41 countries for 11, 13 and 15 year olds.

Eating habits - Daily fruit consumption varies between countries, is highest for 11 year olds and declines with age. Boys are less likely than girls to report eating fruit, as are those from less affluent families in almost all countries. The daily consumption of soft drinks also varies cross-nationally and tends to be higher among older adolescents. Consumption of soft drinks is associated with low family affluence in a majority of the countries, except in eastern Europe and the Baltic states where the reverse is found. Eating breakfast on school days decreases with age. Those from less affluent families, particularly in northern and western Europe are less likely to eat breakfast every school day.

Measurement ...

Studies related to adolescents have measured dietary intake and eating habits in several ways:

- Recall of intake of fruits and vegetable and how much and how many servings per day; recall of sugar intake and how many added sugar drinks or foods and amounts were consumed daily; sodium and potassium intake daily; eating of breakfast; eating fats foods; and eating at home or in restaurants have been used in adolescent studies of risk factors. Recall is often recorded in a survey taken at one point in time, but requiring recall and reflection on daily or weekly intakes. Sometimes. participants are asked to choose from described levels of intake on a pre-determined Likert scale to describe their dietary habits.

- Daily diaries have also been used in studies, where the adolescent records and tracks what they eat and when.

- $\quad$ Studies related more to obesity management and weight control have given a suggested diet to participants and they record levels of adherence to the protocol for food intake. In some cases, an established diet that has been approved such as a special heart and diabetic diet or the Canada Food Guide (Health Canada, 2011) and other respective nationally accepted standards are part of the intervention and the evaluation.

A report on Dietary Reference Intakes for energy, carbohydrate, fiber, fat, fatty acids, cholesterol, protein and amino acids (2002/2005) was produced by the Institute of Medicine of the National Academies, with input from Canadian scientists. It presents a comprehensive set of reference values for nutrient intakes for healthy U.S. and Canadian individuals and populations (by age and risk characterization). 


\section{SUGGESTED DIETARY ADVICE}

5 servings of fruits and vegetables per day

Low sodium intake

Reduce added sugars

Eat breakfast daily

Increase sources of fiber

\subsubsection{Physical activity/inactivity as cardiovascular risk factors in adolescents}

Introduction ...

Regular physical activity has cardiovascular benefits. Increasing regular activity and decreasing sedentary activities such as watching television and playing video or electronic games have been found to be important components of paediatric obesity prevention and therefore, important to lowering of a CV risk factors (Robinson, 1999; Williams et al. 2002;). Physical activity has also been a included in the treatment protocol for obesity and weightreduction trials to combat obesity (Kreb et al., 2003; Gutin \& Owens, 1999). Researchers have found that inactivity, particularly television watching is an important factor in the development of obesity, one of the main factors associated with cardiovascular risk (Andersen et al., 1998; Gordon-Larsen et al., 2002; Gortmaker et al., 1996). Sedentary activity also involves the use of computer, cell phone or other electronic devices for texting, communication or entertainment.

Sample studies ...

Maggio et al., (2010) studied long-term follow-up of CV risk factors after exercise training in obese children in Switzerland. The beneficial effects of physical activity on CV risk factors and BMI was previously demonstrated in their research. This study was to determine if those changes were maintained 2 years later. They involved 20 of the 38 from the previous study in the follow-up study. The mean 24-hour diastolic blood pressure significantly decreased; while systolic blood pressure was slightly reduced. BP changes were greater in children who diminished their BMI compared with ones who did not. In addition, the arterial intima-media thickness, BMI, body fat, and physical count remained stable two years after to indicate that the positive effects remained for that period after the exercise training was initiated.

Buchan et al. (2011), in Scotland studied the effects of time and intensity of exercise on novel and established markers of CVD in adolescents. Brief, intense exercise, compared to traditional endurance exercise was studied in 47 boys and 10 girls, $16.4(+/-0.7)$ years of age. Three weekly sessions were conducted over 7 weeks for three groups: moderate exercise (MOD), high intensity exercise (HIT) or the control group. They engaged in 4-6 repeats of maximal sprint running or 20 minutes continuous running. Significant improvements were found in systolic blood pressure, aerobic fitness and BMI in the HIT group. Significant improvements were found in aerobic fitness, percentage of body fat $(\% \mathrm{BF}), \mathrm{BMI}$, fibrinogen (Fg), plasminogen inhibitor-1, and insulin concentrations in the MOD group. They concluded that exercise is beneficial, but brief intense exercise may be a time-efficient means for improving CVD risk factors in adolescents

In a U. S. study of a nationally representative sample of 12,759 participants in the National Study of Adolescent Health Gordon-Larsen et al (2002) collected data on moderate to vigorous 
and low-intensity physical activity (TV/video viewing, and videogame/computer use) by questionnaire. Multivariate analysis assessed the association of overweight by BMI, with initial and one year changes in activity and inactivity levels, controlling for age, ethnicity, socioeconomic status, urban residence, cigarette smoking, and region of residence. Overweight prevalence was found to be positively correlated with high levels of TV/video viewing among white boys and girls. The odds of being overweight decreased with high levels of moderate to vigorous physical activity among white, non-Hispanic black boys and girls, and Hispanic boys and girls.

In the next cycle of the same survey, an increase in physical activity was found to be associated with decreasing relative BMI in girls and overweight boys. An increase in inactivity (daily TV/videos/video games) was associated with increasing BMI in girls (Berkey et al. 2003). Activities that were found to be accessible and beneficial to most children were aerobic dancing and walking.

World Health Organization (WHO, 2008): Health behavior in school-aged children international report from the 2005/2006 survey in 41 countries for 11, 13 and 15 year olds.

Physical activity - Young people should participate one hour or more of at least moderate physical activity every day. Less than half of young people do so in almost every country and region. Slovakian boys and girls are most likely to meet the guidelines in every age group. Across countries and regions and all age groups, girls are less active than boys and the gender gap increases with age. Fifteen year olds are less likely (average 16\%) to report meeting the guidelines than 11 year olds (average 26\%) in the majority of the countries. In under half of the countries, those from more affluent families are more likely to meet guidelines.

\section{Measurement ...}

Measurement of sedentary activity has primarily been conducted by self-report recall of number of hours estimated of video game/computer use, TV/video/DVD viewing, and cell phone use and texting, daily or weekly. Most studies have the individual estimate times in a one-time administered survey; however the use of a diary over a period of time to record daily activities has also proven to be effective. For exercise, both self report and actual testing have been used and quantified. Self-report surveys ask questions about types of exercise the adolescent engages in (cycling, running, swimming, walking), how often, at what level of intensity, and for what time duration. In addition, physical exercise testing has also been used with adolescents completing activity tests in a school setting such as the shuttle test (Flouris et al. 2008) or being observed and tested in a laboratory setting. In a study by Buchan et al. (2011), a group engaged in moderate level activity, and one in high level activity and a control group and correlated the time and intensity data with established markers of CVD in participating adolescents.

\section{SUGGESTIONS FOR PHYSICAL ACTIVITY}

Regular aerobic activity (30-60 minutes of moderate physical activity on most days) Limit sedentary activities (under 2 hours per day) 


\subsubsection{Hypertension, high blood pressure as a CV risk factor in adolescents}

Introduction ...

Hypertension has been linked to cardiovascular diseases, stroke and kidney disease (Chobanian et al, 2003). The medical management or control of blood pressure is thought to reduce the risk of serious cardiovascular disease. In obese or overweight adolescents, and the known early development of atherosclerosis in children, identification and treatment of blood pressure in children is essential (Luma \& Spiotta, 2006).

Sample studies ...

Rafraf et al. (2010) conducted a cross-sectional study in Iran to determine the blood pressure status and its relationship to BMI in 985 girls attending high school. Blood pressure, BMI (weight and height) was calculated and blood pressure measured as normal, prehypertension or hypertension was calculated using the 2004, Fourth Report blood pressure screening recommendations. Overweight and obesity were defined according to International BMI cutoff points for adolescents. The prevalence of pre-hypertension was $13.9 \%$ and hypertension was $19.4 \%$ in the sample. Overweight and obesity rates were $2.8 \%$ and $16.4 \%$ of the subjects respectively. The prevalence rates of hypertension and prehypertension increased with increasing BMI. The prevalence of high blood pressure in adolescent girls was higher than in other countries, despite a lower prevalence of obesity. They suggested taking blood pressure readings during at least 3 visits for increased accuracy in future studies.

Measurement of blood pressure in children and adolescents ...

Measurement of blood pressure is a component of an assessment of cardiovascular risk. Identification of pre-hypertension and then continued monitoring of blood pressure is one method identified to decrease the risk of further cardiovascular disease. The Fourth Report on the diagnosis, evaluation, and treatment of high blood pressure in children and adolescents (2004) was prepared by the National High Blood Pressure Education Working Group. "Considerable advances have been made in detection, evaluation, and management of high blood pressure (BP), or hypertension, in children and adolescents. Because of the development of a large national database on normative BP levels throughout childhood, the ability to identify children who have abnormally elevated BP improved. On the basis of developing evidence, it is now apparent that primary hypertension is detectable in the young and it occurs commonly" (p. 555). The long-term health risks can be substantial and it is important that clinical measures be taken to reduce these risks and optimize health outcomes. The report reviews appropriate and specific approaches, including the administration of pharmacologic therapy for childhood hypertension (p. 567).

Current standards adopted for the identification of pre-hypertension and hypertension in children were outlined in The National High Blood Pressure Education Program Working Group on High Blood Pressure in Children and Adolescents (2004). In this document, the authors outlined the definition of hypertension particularly as it relates to children and adolescents:

- Hypertension is defined as systolic blood pressure (SBP), average SPB and/or diastolic $\mathrm{BP}$ (DBP) that is $\geq 95$ percentile for gender, age, and height on $\geq 3$ occasions. 
- Pre-hypertension in children is defined as average SBP or DBP levels that are $\geq 90$ percentile but $<95^{\text {th }}$ percentile.

- As with adults, adolescents with blood pressure readings $\geq 120 / 80 \mathrm{~mm} \mathrm{Hg}$ should be considered pre-hypertensive.

A patient with BP levels $>95^{\text {th }}$ percentile in a physician's office or clinic, who is normotensive outside a clinical setting, has "white-coat hypertension." Ambulatory BP monitoring (ABPM) is usually required to make a diagnosis. (National High Blood Pressure Education Working Group on High Blood Pressure in Children and Adolescents, 2004, p. 556).

\section{SUGGESTED ADVICE FOR HIGH BLOOD PRESSURE}

Be aware of family history and parents and siblings with high blood pressure Have blood pressure tested earlier in childhood and adolescence and into adulthood Monitor blood pressure regularly if there are signs of hypertension

\section{Exercise}

Eat well

Lower sodium intake

\subsubsection{Cholesterol as a CV cardiovascular risk factor for adolescents}

Introduction ...

Cholesterol screening is also important for children and adolescents as hypderlipidemia is a known risk factor for the development of cardiovascular disease (McCrindle, 2000). Furthermore, the atherosclerotic process has been shown to begin in childhood (McGill et al., 1997; Newman et al., 1986).Treatment of high cholesterol has been proven effective in reducing cardiovascular disease and death in adults (McCrindle, 2000). Early detection and treatment of hypderlipidemia in children is indicated.

Sample studies ...

Manios et al. (2003) conducted a twenty-year study of the dynamics in adiposity and blood lipids of Greek boys 12.2 (+/ - 2.3) years of age. They recruited 277 in 1982 and 251 in 2002. They calculated height and weight for BMI, as well as plasma lipid concentrations to compare across cohorts for the 2 years. Significant changes in total cholesterol (TC) were observed for urban, but not rural boys. Regional differences reported that urban boys were taller, heavier and had higher BMI values and higher LDC-C concentrations. They found changes in anthropometric changes and lipids and suggest a national strategy to monitor and address some of these risk factors.

In order to obtain information about the concentrations of LDL cholesterol and total cholesterol in children and adolescents in the United States, Ford et al. (2009) conducted a study of children ages 6-17 years age. Using data from the National Health and Nutrition Examination Survey (NHANES) 1999- 2006, measurements for total cholesterol and fasting LDL cholesterol were examined. Of the 2,724 LDL cholesterol levels examined for participants aged 12-17, the mean concentration was $90.2 \mathrm{mg} / \mathrm{dL}$ and for total cholesterol the mean concentration for participants aged 6-17 years was $163.0 \mathrm{mg} / \mathrm{dL}$. The researchers noted that approximately $0.8 \%$ of the $12-17$ years olds would most likely be eligible for pharmacological interventions for their elevated LDL cholesterol levels. 


\section{Measurement ...}

Standards for a cholesterol screening program for children were developed from the National Cholesterol Education Program (NCEP) of the National Heart, Lung and Blood Institute in the United States in 1992. Their approach includes screening children who have a family history of premature cardiovascular diseases or a family history of high cholesterol levels. They further recommend that children who have no known family history, or have other risk factors for cardiovascular disease should also be screened (Daniels, Greer \& The Committee on Nutrition, 2008). Acceptable levels include a total cholesterol $<170 \mathrm{mg} / \mathrm{dL}$, borderline 170-199 mg/dL and elevated $>200 \mathrm{mg} / \mathrm{dL} /$. Acceptable levels for low density lipoprotein are, $100 \mathrm{mg} / \mathrm{dL}$ borderline $110-129 \mathrm{mg} / \mathrm{dL}$, and elevated > $130 \mathrm{mg} / \mathrm{dL}$.

\section{SUGGESTED ADVICE FOR CHOLESTEROL}

Be aware of family history

Get tested and monitor levels

Eat well and avoid certain fats in the diet

\subsubsection{Obesity as a CV risk factor in adolescents}

\section{Introduction ...}

The prevalence of overweight and obesity in children is increasing rapidly and the ongoing obesity epidemic represents a major public health burden world-wide (Ebbeling et al., 2002; Daniels et al., 2009). Obesity is thought to pose a major risk of morbidity and premature mortality in adulthood for those affected by cardiovascular disease. Obesity is identified as an independent risk factor for cardiovascular diseases and it significantly increases risks of morbidity and mortality. Childhood obesity is a global phenomenon affecting all socioeconomic groups. "Aetiopathogenesis of childhood obesity is multi-factorial and includes genetic, neuroendocrine, metabolic, psychological, environmental and socio-cultural factors" (Raj \& Kumar, 2010, p. 598).

The treatment and prevention of obesity often requires an interdisciplinary and holistic approach that includes: dietary management, increases in physical activity, restriction of sedentary behaviours, and psychotherapy and counseling. Pharmocology and bariatric surgery have also been included in the approaches used to deal with this pervasive and urgent health issue that often begins in youth. Doak et al. (2006) conducted an international review of interventions and programs in the prevention of obesity in children and adolescents. Flynn et al. (2006) did a synthesis of the evidence available on reducing obesity and related chronic disease risk in children and youth and summarized best practices and recommendations for improved approaches. They created an algorithm to guide the research process and the study of obesity with children and youth.

\section{Sample studies ...}

A U.S study examined the importance of age in the relationship of childhood obesity and cardiovascular disease risk factors in adulthood as part of the Bogalusa Heart Study. Freedman et al., 2001). They assessed the longitudinal relationship of childhood BMI to all levels of lipids, insulin and blood pressure among 2,617 participants. All participants were initially examined at ages 2 to 17 years and were re-examined at ages 18 to 37 years; the 
mean follow-up was 17 years. Of the overweight children initially identified, $77 \%$ remained obese as adults. Childhood overweight was related to adverse risk factor levels in adults, but the associations were weak. Although obese adults had adverse levels of lipids, insulin and blood pressure, levels of these did not vary with childhood weight status, or with age. The need for primary and secondary prevention was suggested.

A study by Barnabe et al (2010) in Brazil included 4,138 high school students (14-19 years) selected by cluster sampling in two stages. They obtained data using the Global School-based Health Survey, and anthropometric measurements were taken for determination of overweight and abdominal obesity. The identification of cases of abdominal obesity was performed by waist circumference analysis, using age and gender-related cutoff points as reference. Logistic regression was used for analysis of behavioural factors associated with the occurrence of abdominal obesity. They found the prevalence of abdominal obesity to be $6 \%$, slightly higher for girls and lower than international estimates. Physical activity was significantly associated with the occurrence of obesity.

World Health Organization (WHO, 2008): Health behavior in school-aged children international report from the 2005/2006 survey in 41 countries for 11, 13 and 15 year olds.

Overweight - The data presented on overweight and obesity are derived from selfreported height and weight information used to calculate body mass index (BMI), not from actual measurements, and so need to be treated with some caution. The general term 'overweight' included two groups: those who are considered obese and those who are considered overweight, but not obese. The proportions of 13 to 15 year old boys and girls who are overweight range from $4 \%$ to $35 \%$ across countries and regions. Canada, Greenland, Malta and the United States have among the highest rates. Boys, and those from less affluent families report higher levels of overweight and obesity, particularly in North America and western Europe.

Measurements...

\section{Body Mass Index measurement and levels in children and adolescents}

Given the increasing focus on the prevalence of obesity in children and the health care risks associated with obesity including cardiovascular disease risk, close assessment and monitoring of children's growth is key to awareness and primary prevention. One common measurement that has been used to measure overweight in adults is the body mass index (BMI) (weight/height) (Cole et al. 2000). Although a cutoff point of $30 \mathrm{~kg} / \mathrm{m}$ has been suggested as an international reference for overweight adults (World Health Organization, 1995) currently no consistent standard cut- off point exists for children. In fact, several BMI reference standards: the Centre for Disease Control (CDC) in the United States; The World Health Organization Child Growth Standards; the United Kingdom 1990 BMI; and the standard definitions developed by the International Obesity Task Force are available for use with children (Flegal \& Ogden, 2011). When using BMI cutoffs with children, the age, height, weight and sex of the youth must be considered. Monitoring children's growth and development is a key assessment factor.

\section{Waist Circumference}

Waist circumference is another common screening measurement used in tandem with the BMI. Waist circumference is an indicator for central adiposity (World Health Organization, 
2011) and has been used as a predictor for the development of cardiovascular disease (Lee, Huxley, Wildman \& Woodward, 2008) and diabetes (Huxley et al., 2010). Similar to the BMI, there is no one standard criteria percentile for waist to hip circumference for children and adolescents due to differences in growth rates and patterns among different population groups (Ma et al., 2010).

\section{SUGGESTED ADVICE}

Increased, regular physical exercise

Dietary management

Restrict and reduce sedentary activity

Weight monitoring, control and reduction

\subsubsection{Family history as a CV risk factor}

\section{Introduction ...}

It has been well established that the family is the primary context in which health behaviours are learned, performed and developed over time (Allen \& Warner, 2002; Laudenbauch \& Ford-Gilboe, 2004). It has also been well established that family history of heart disease increases an offspring's chances of developing $\mathrm{CV}$ risk factors and $\mathrm{CHD}$ (McCusker, et al. 2004; Michos et al., 2004). This is true, particularly if a first degree family member (father, mother, or sibling) had a heart attack (O'Donnell, 2004). Parental history of CVD has been studied well and the coronary artery calcification sibling history has also been found to be more strongly associated than parental history (Nasir et al., 2004).

"Health work is positively influenced by the health potential of the family - the strengths, motivation and resources of the family unit and its members - as well as the extent to which nurses and other health professionals can use a strength-based, situation-responsive approach when working with families" (Laudenbach \& Ford-Gilboe, 2004, p. 125). How heredity and genes play a part is still being studied, but the connections are clear. It is suggested that those with a family history of heart disease start early with reducing lifestyle risk factors. If family history indicates a genetic predisposition to heart attack, individuals are vulnerable to developing other contributing risk factors such as diabetes, obesity or high blood pressure.

\section{Sample studies ...}

Murabito, in the Framingham Offspring Study (2004) studied 2,475 participants and over eight years compared the occurrence of heart disease in people with or without siblings. They found participants who had a brother or sister with cardiovascular disease had higher levels of risk factors than those without the disease. This association had a $45 \%$ increased risk for the disease.

A cross-sectional study of families was conducted with nearly 8,500 adults in Ohio, U.S.A. with half older than 52 and half younger than 52 (Nasir et al., 2004). Family history of heart disease in the study was defined as a sibling or parent experienced fatal, or non-fatal heart attack or underwent some form of coronary revascularization, including bypass surgery by age 55. Signs of calcification and plaque build-up were observed in all groups, regardless of 
family history, but the burden was greatest among those who had a parental or sibling history of early heart disease, ranging from $36 \%$ to $78 \%$ for both men and women. These data support rigorous preventive measures should be taken by individuals with a history of premature heart disease.

Sdringola, Patel and Gould (2001) hypothesized that asymptomatic persons with coronary artery disease (CAD) had myocardial perfusion defects on positron emission tomography (PET) as markers of early CAD. After medical and family histories were taken and tests were conducted. This study documented the presence of quantitative, statistically significant, dipyridamole- induced myocardial perfusion abnormalities on PET in $50 \%$ of asymptomatic persons with a parent or sibling with CAD, independent of risk factors, to indicate preclinical coronary atherosclerosis.

Measurement ...

The Health Options Scale (HOS) is a 21 item version that has been used in studies of families who varied in structure, stage of the life cycle, socioeconomic status (SES) and the study of types of health challenges they face (Ford-Gilboe, 2002; Ford-Gilboe, 1997; Laudenbach \& Ford-Gilboe, 2004). It has been used as a valid and reliable measure of health with mothers and preadolescent children, with adolescents and with women as sources of information about families and their health. Schuener (2004) summarized the clinical application of genetic risk assessment strategies for coronary heart disease involving both genotypes and primary care approaches.

\section{SUGGESTED ADVICE FOR THOSE WITH A FAMILY HISTORY OF CVD}

Assess family history of CVD and risk factors

Have family dialogue for awareness

Health check-ups and regular surveillance

Test risk factors such as blood pressure and cholesterol earlier

Quit smoking

Cut back on fatty foods

Increase exercise

Know your past - act in the present - Protect your future (The Chronic Disease Genomics Project)-

Explore use of medications with a healthcare professional

\subsubsection{Sample studies of other cardiovascular risk factors and their associations with CVD in adolescents}

Diabetes ...Type I Diabetes (TID) is a common disease of childhood and is increasing worldwide (Onkamo et al., 1999). Cardiovascular disease has been found to occur at a higher frequency and at a younger age in patients with TID compared to the general population (Laing et al., 1999; Libby et al., 2005).

A cross-sectional study by Krishnan et al.,(2011) examined the presence of cardiovascular risk factors in normal and overweight children, with and without TID in a sample of 66 children 16-22 years of age. A fasting blood sample was analyzed for a lipid profile (triglyceride cholesterol, high density lipoprotein cholesterol), and low-density cholesterol, 
apolilipidprotein B (apoB), and apolipoprotein C-III (apoC-III) levels. Body composition was measured by dual energy x-ray absorptiometry and vascular elasticity by HDI/Pulsewave CR-2000. Statistical analysis examined the effect of TID and body weight status and their interaction on cardiovascular risk factors. The study was unable to demonstrate an additive effect of body weight and TID on cardiovascular risk profiles with well-controlled children and adolescents with TID. However, there was a direct relationship of small artery elasticity to body weight that indicated further investigation was warranted.

Park et al., (2007) explored family history of diabetes and risk of atherosclerotic cardiovascular disease (ASCVD) in a cohort of 1,005,230 Koreans aged 30-95 years who were insured by the National Health Insurance Corporation who had a biennial medical evaluation during 1992-1995. The risk of ischemic heart disease (IHD) increased significantly in men, but not in women. Men with both diabetes and IHD were at significantly increased risk of developing IHD, ASCVD and cerebrovascular disease. This study demonstrated that risk of ASCVD is increased among those who have diabetes and a family history of diabetes, suggesting that genetic factors may increase the risk of ASCVD.

Depressive symptoms ...

A study on depressive symptoms and subclinical markers of cardiovascular disease in adolescents was conducted by Dietz and Matthews (2011) with 157 black and white adolescents 16-21 years of age. The study was of psychosocial stress and cardiovascular risk factors with measurements of arterial stiffness as tested by pulse wave velocity (PWV) and intima media thickening (IMT). The Center for Epidemiological Studies Depressive Scale and the Cook-Medley Hostility Inventory subscales were used and described (Dietz \& Matthews, 2011). Linear regression controlled for socio-demographic variables, health behaviours, blood pressure, BMI and heart rate. More severe depressive symptoms were found to be associated with higher levels of PWV, but not with IMT. Adolescent depression remained a significant predictor of PWV when controlling for adolescent hostility. More study is indicated regarding depressive symptoms and the pathogenesis of CVD.

Socio-economic status (SES) ...

A Canadian study conducted by Schreier and Chen (2010) examined socio-economic status in one's childhood as a predictor of offspring cardiovascular risk. The literature was reviewed in the Canadian study that demonstrated living in a low socioeconomic status (SES) is linked to poorer health (Adler \& Newman, 2002). A strong relationship has been demonstrated between low SES and increased mortality (Andersen et al 1997); between low SES and specific risk factors for diseases such as cancer (Conway et al, 2008; Shakley \& Clark 2005); and diabetes (Eversen et al, 2002). One of the most consistent associations has been found between SES and cardiovascular disease (Kaplan \& Keil, 1993; Pollitt et al, 2005) and stroke (Cox et al, 2006). Low SES and specific risk factors of blood pressure, cholesterol and subclinical CVD have also been studied (Appel et al., 2002; Colhoun et al., 1998; Grotto et al, 2008).

The Schreier and Chen study tested whether effects of socio-economic environments (as reported in 4 quintiles) persist across generations by examining the parents' childhood and if SES of the parents could predict blood pressure trajectories in their youth offspring. A sample of 88 healthy youth whose mean age was 13 (+/- 2.4 years) were involved in a 12 
month study period including 3 study visits, each 6 months apart. If the parents' childhood SES was lower, children displayed increasing SBP and CRP and if it was higher, the reverse was found to be true. The study pointed out that intergenerational histories are important and SES is important. Improving overall socio-economic levels for all by a population health approach might have a positive effect on adolescent and adult cardiovascular disease.

\section{Hormonal contraception ...}

Du et al. (2011) in a German study of hormonal contraceptive (HC) use in 2, 285 girls, 13-17 years of age. They compared users of $\mathrm{HC}$ and nonusers with the prevalence of cardiovascular risk factors, including systolic and diastolic blood pressure and serum concentrations of lipids, lipoproteins, high-sensitivity C-reactive protein (hs-CRP) and homocysteine. Users were more likely than nonusers to combine several behaviour-based health risks independent of socio-demographic factors. In particular, HC was strongly associated with current smoking. HC use and behavioural factors showed an additive effect on biological cardiovascular risk factors, explaining between $6 \%$ and $30 \%$ of the population variance. It is suggested that physicians, when prescribing $\mathrm{HC}$, should systematically assess avoidable cardiovascular risk factors and provide counseling tailored to the risk profile of the individual patient.

Sleep apnea and deprivation and cardiovascular risk in children and youth...

In obese children, obstructive sleep apnea (OSA) has been linked to the early onset of cardiovascular morbidity and metabolic morbidity (Spicuzza, et al., 2008). The potential association between children with obstructive sleep apnea syndrome and blood pressure elevation has been explored; however, further investigation of this association is warranted (Bhattacharjee et al., 2009). Similarly, non-obese children with OSA have been shown to be at risk for endothelial dysfunction, necessitating further longitudinal studies of children with OSA and its impact on cardiovascular disease (Gozal et al., 2007). Studies in adults indicate that too little or too much sleep is associated with stroke and risk of CVD.

Cappuccio et al. (2011) from the University of Naples conducted a systematic global review and meta-analysis to assess the relationship between duration of sleep and later development of coronary heart disease (CHD) or stroke, as well as death from those diseases. They included studies where participants were free from disease at baseline. Normal sleep was classified as 7-8 hours; short sleep as less than, or equal to 5-6 hours; and long sleep as more than 8-9 hours. They pooled the risk figures for the associations between sleep duration and cardiovascular disease development, or death. The review included 15 studies on 24 cohorts covering 474,684 adults from eight countries. The duration of the follow-up was 6.9 to 25 years. They studied 16,067 cases of fatal and non-fatal cardiovascular events: 4,169 cases of CHD; 3,478 strokes; and 8,420 other CV events. They found that short sleep, compared to normal sleep was associated with increased risk of developing or dying from stroke, as was long sleep. For studies examining total CVD, researchers found that compared with normal sleep, long sleep was associated with increased risk of CVD. Both short and long sleep durations were found to be potential predictive markers of CVD outcomes.

Oureshi et al. (1997) explored the association between sleep duration and daytime somnolence (most always taking naps) with the incidence of stroke and CVD in a U.S. 
national cohort of 7, 844 adults from the 1st National Health and Nutrition Examination Survey Epidemiological Follow-up Study over a 10 year follow-up period. After adjusting for age, race, gender, education, smoking and some of the other risk factors, the risk of stroke was increased for those who sleep more than 8 hours a day, compared to 6-8 hours. Similar results were found for the risk of CVD, although not found to be statistically significant.

\section{Research and the study of adolescent cardiovascular health and risk}

\subsection{Research methodology}

A majority of the research studies regarding adolescent cardiovascular risk factors reported in this chapter have been quantitative in nature. Quantitative research design can be nonexperimental or experimental. Many epidemiological studies trending the prevalence of risk factors have been conducted using non-experimental cross-sectional survey data with various age groups and cohort sample populations. Trends have been reported with accompanying statistical analysis and tests to determine correlations or associations between and among the risk data. A few studies have been conducted with the same cohort in longitudinal designs, many over several years in studies conducted at the international, national and smaller community sampling levels. The variation apparent in the methods used; population sample age representation and selection process; and the approaches used for analysis and reporting make it difficult to have a truly accurate and comparable picture of cardiovascular risks from childhood, adolescence into adulthood. Even with all the challenges, the body of evidence is mounting and sounding an alarm. Regularly scheduled and reliable surveillance and mandatory staged testing of $\mathrm{CV}$ risks at several age points is beginning to make sense.

Studies are evident that include an evaluation of risk factors before and after specific interventions are introduced to reduce the risk factors with adolescents (i. e. the impact of physical activity or improved nutrition and the resultant impact on other risk factors). Only a few studies have used experimental designs and control group approaches to compare results.

Most studies have been conducted through schools or clinics with convenience samples, with only a few national strategies using random or stratified sampling approaches. Research Instruments and measurement standards have been developed over time and the reliability and validity of questions, surveys tools and designs have been tested. Measurements and standards relating to blood pressure, cholesterol testing and some activity testing have been developed or adapted specifically to the paediatric and adolescent populations.

Few qualitative studies have been conducted of a phenomenological nature to explore the lived experience of cardiovascular risks (such as obesity) in adolescents. We need to know more about what life is like for adolescents and what the meaning of the phenomenon is to those who live it. (i.e. smoking or not being active) so that our interventions are more effective. Ethnographic studies might help us to also understand the patterns and experiences of specifically defined cultural groups. This may help us to understand what the numbers really mean when they indicate there are differences in risk factors in different 
regions of the world, in different schools, in different ethno-racial adolescent groupings and in different age groups for adolescents. We might understand more about why exercise decreases or smoking increases in certain subsets of adolescents and be able to target our efforts more effectively..

\subsection{Research instruments used in the study of adolescent cardiovascular risk factors}

A variety of tools and scales have been tested in many of the studies described herein. A summary of the types of research tools used in the study of adolescent cardiovascular health are:

- Self-reported survey questionnaires of lifestyle behaviours are mostly collected by paper and pen survey or questionnaire administered in person, in group settings, over the telephone, through the internet or through a guided health interview.

- Physical assessment tests often include tests or measurements to determine blood pressure; cholesterol fasting and non-fasting levels; height and weight to calculate BMI; waist circumference; physical activity levels; and stress responses. Many of these tests require specialized equipment, processes and protocols so they are measured and interpreted in the same way. Some tests require trained staff to conduct the test, read the results and work with clients for feedback, consultation and follow-up. Some tests are best conducted in laboratory, clinical or school settings.

- Self monitored and recorded diary entries have been used as effective research tools in some studies for adolescents to track their own nutrition, smoking and physical exercise, daily and weekly over established periods of time. Diaries are handed in for quantification and analysis. Diaries can also be used to collect qualitative data about inner reflections, perceptions, attitudes and experiential information for analysis to establish core themes or to develop theories or models to guide practice from the data through grounded theory approaches,.

- Use of existing reliable and valid instruments to assess stress, depression, self esteem, or hostility. Many studies related to adolescent cardiovascular disease have also added existing social science instruments that have been developed to measure a wide range of topics from assertiveness, self-esteem, and hope. This information has been used to correlate with $\mathrm{CV}$ risk factors in the search for possible associations that impact on $\mathrm{CV}$ risk or have a mediating or protective effect.

- Use of family history data. Only a few adolescent studies used a family history of heart disease or health survey. Few also included a process by which the adolescent and parent were encouraged to have a dialogue about exploring family history and health data related to heart health, cardiovascular disease, diabetes, high blood pressure or cholesterol abnormalities in parents, siblings or grandparents as part of the research or as part of the awareness strategy.

- Mortality and autopsy data. Studies of adolescent cardiovascular risk data have involved autopsy data and mortality statistics. The collection and reporting of this data has been included in studies related to family history and parental and sibling data or in longitudinal tracking studies such as the Framingham study. Should some of the crosssectional cohort studies track the same individuals over time, we could have more data on the final outcomes of the early identification of $\mathrm{CV}$ risk factors and morbidity and mortality outcomes. The case for genetic testing, counseling and intervention earlier for 
high risk cases is emerging in many areas of health risk and heart disease certainly is an area of high risk.

Sample instrument ...

Many instruments have been developed about health and lifestyle factors related to youth in many of the projects reviewed in this chapter and there are many more in existence around the world. Only a few sample ones will be presented here. Surveys related to health and lifestyle have been developed by research collaborators and used in 52 countries called the Health Behaviours in School-aged Children (HBSC) (Yusef et al., 2001, 2008; WHO 2008). The $\mathrm{CATCH}$ instruments have been developed and used in many school projects in the U.S. along with surveys used in the Bogalusa studies. In Canada, the instruments used in the Census, Canadian Community Health Survey elicit and trend information about aspects of health and lifestyle for adolescents. The lifestyle survey components of the Niagara Healthy Heart School's Program has been adapted and widely used for almost a decade. Reed et al. (2007) developed and tested an instrument that measures and calculates the number and severity of cardiovascular risks in children and adolescents to determine an overall Healthy Heart Score (from 1-18) that could be used in develop a risk profile to be used in the identification of those at risk for intervention.

Stanton, Willis and Balanda (2000) conducted a study in a project in Australia to develop a survey to be used with secondary school students to monitor relevant health-related behaviours and the inter-relationship between them, with an emphasis on identifying clustering behaviours of negative outcomes with 12 to 18 year olds. They included a compendium of existing surveys. They described the stages to develop and test a survey for use with adolescents: draft stage, pilot testing, and formal and informal evaluation of the instrument. They included 308 juniors and 223 seniors in high school, of which $10 \%$ took part in testing the instrument for reliability and giving input to the researchers. They suggest further analysis and testing of a hopelessness scale be included.

\subsection{Research limitations to date in the study of adolescent cardiovascular risk factors}

A few of the major limitations in adolescent cardiovascular risk research will be reviewed.

\subsubsection{There are few studies about adolescent CV risk factors using the same measurements and instruments and methodology to make comparisons possible ...}

Sample studies ...

Three countries; England, Finland and Norway participated in the $1^{\text {st }}$ Health Behaviours in School-aged Children (HBSC) in 1982. By 1985, 11 countries were involved and the WHO Regional Office for Europe began to play a coordinating role. Canada was invited as an associate member to participate in the 1993-4 and 1997-98 cycles. Twenty eight countries participated for the 2001-02 school year. Fifty two (52) countries are now involved. The HBSC is representative of the population health approach used in Canada and incorporates the determinants of health that include the home, school, social environment, individual health practices and gender.

The advantage of HBSC is to be able to compare and contrast youth responses to the same questions country to country. Combined data and individual country data are developed 
into national reports to guide health promotion in their area (i. e. The Health of Canada's Youth Report (King \& Coles, 1992) was published by Health Canada; the 2nd report the Health of Youth (King et al. 1996) .

The HBSC was administered in classrooms in grades 6, 8 and 10 and grade equivalents in Quebec. Questions were developed by HBSC collaborators in an attempt to create a developmental perspective in order to examine changes in attitudes and behaviours from the onset of puberty to the middle years of adolescence. The research identifies health indicators and the factors that may influence them (smoking, alcohol use, level of physical activity, psychosocial states such as happiness and loneliness; and physical problems such as headaches and backaches). It also explores health influencing factors or determinants of health that include the school, parents, peers, and individual characteristics. Additional items regarding bullying were added in 1998.

Canada's study was based on a systematic single cluster procedure being the school class. They identified the potential number of grade 6, 8, 10 classes listed with 25 per class. A sample of 80 classes per grade was randomly selected to reach a sample size of 2000 per grade level. Other countries used a variety of sampling procedures. Ideally, it is suggested that surveys should be conducted at the same time each year. Ten countries were selected from the 23 to compare with Canada in the second survey that had structural factors in common or had policies and programs in place of interest. Five composite measures compared student relationships to parents; adjustment to school; self-esteem; social integration and; diet. The study also reported on relationships between the data (i.e. use of marijuana and smoking; and marihuana use and how you feel about school).

\subsubsection{There are few longitudinal studies to track cardiovascular risk factors over the lifespan to track the development of CVD into adulthood}

Sample longitudinal studies ...

Kavey (2010) reported on the analysis of the data from the National Health and Nutrition Examination Survey (NHANES) from 2007 to 2008 (Ogden et al., 2002) that indicated that $16.9 \%$ of children and adolescents had a BMI greater than the $95^{\text {th }}$ percentile. There was a significant increase in boys 6-19 years of age. The community screening of 5-17 years olds in The Bogalusa Heart Study revealed that the prevalence of obesity increased more than fivefold from $5.6 \%$ in $1973-1974$ to $30.8 \%$ in $2008-2009$. Information from these longitudinal studies indicates that children with high BMI have a strong chance of becoming obese and developing serious conditions such as hyperinsulinemia/type 2 diabetes, hypertension and dylipidemia beginning in childhood and premature heart disease in adulthood.

A longitudinal tracking of adolescent health behaviours in two Minnesota Heart Health Program communities in the United States was conducted. Beginning in sixth grade, (1983) seven annual waves of behavioural measurements were taken (baseline $n=2376$ ). Selfreported data included smoking, physical activity and food preferences. The results showed a progressive change in weekly smoking status; as they began to experiment with smoking, they were more likely to remain a regular smoker. In physical activity and eating good foods, those who measured high at baseline, were more likely to remain high. This study reported some evidence of the early consolidation of habits in these three risk factor areas. 
Intervention before grade six and before behaviour patterns become resistant to change is indicated. A cessation program is offered to those having trouble quitting.

\subsubsection{There are few qualitative studies on adolescent cardiovascular risk factors}

Qualitative studies can explore the experiences, perceptions, feelings and meanings as lived by the adolescent regarding a variety of phenomenon associated with heart risks and healthy behaviours. We have increasing alarming numbers and trends clearly in evidence before us. We need to know and understand more about what this means to adolescents and why and how they think and feel and change or don't change. The voices, thoughts and meanings of adolescents can add much to our understanding and planning of more effective health promotion or risk reduction approaches.

\subsubsection{There are few studies on adolescents and their follow-up and use of health care providers when identified as having CV risk factors: what works and doesn't for referral, testing, follow-up and lifestyle counseling and change}

There are few follow-up studies about whether adolescents, after being screened or having an awareness of risk and family history actually seek advice, further testing or consultation with a physician or health care provider.

Sample study ...

A qualitative study entitled, Adolescent cardiovascular risk factors: A follow-up study (Kilty \& Prentice, 2010) examined the outcomes of grade nine students who were referred to their physician as a result of having an elevated cholesterol level or elevated blood pressure during a screening by Heart Niagara and a school nurse. The screening assessment was part of the Niagara Schools Healthy Heart Program which is comprised of an educational session on heart health, a screening assessment of blood pressure, height, weight, Body Mass Index (BMI), non-fasting total cholesterol level and a self-reported lifestyle assessment. CPR training is also a component of this program.

Telephone interviews were conducted with 304 participants over a three month period. The interviews included: 126 parent-teen dyads from the same family, 37 parents-only and 15 teens-only. Information on what happened as a result of the referral was queried including: actual attendance with follow-up referrals, medications prescribed, further tests conducted, and referrals to other specialists. Additionally, queries about changes in lifestyle as a result of the screening, awareness and follow-up were also explored.

Fifty percent of those who were referred to their physician for follow-up participated in the qualitative interviews. According to the parents, $63 \%$ of teens went for a follow-up appointment with their health care practitioner. The teens themselves reported that $58 \%$ had gone for follow-up. The reasons given for not following up with the referral were that it was not seen as 'urgent or necessary' or the teen appeared to be fine or was already seeing the physician for other reasons. Given that some adolescent behaviours may contribute to the development of diseases including cardiovascular disease in the future (Kilty \& Prentice, 2010), it is important to understand why adolescents may or may not follow-up with referrals and the potential outcomes of follow-up consultation with a physician when identified as having potential CV risk factors. Early identification and follow-up in community settings can potentially ameliorate risk factors, if identified and treated early. 
A review of information on adolescent help seeking behaviours and barriers to seeking health advice is included along with features of an adolescent friendly health care service delivery.

\subsection{Settings for adolescent research on CV risk factors}

Community settings for making contact with adolescents for research, health promotion and intervention have primarily been through the schools or health clinics and physicians' offices.

The school can be viewed as one of the most important settings in which social and psychological development occurs and it is likely that health and health behaviours may be associated with a relationship to school (Bond \& Compas, 1989). Large numbers of adolescents can be reached for research and health education purposes through schools. Adolescents still have an affiliation with family and varying degrees of independence related to health issues. Researchers have to be aware that in some regions, consent can be completed by the adolescent to participate in research studies, and in other regions, the parent also has to give consent. The school system officials may have to review the research proposal and the attention paid to ethical issues, privacy and confidentiality before proceeding. Since schools are a good place to gather valuable information about adolescent health, efforts to coordinate studies are needed so that the schools and adolescents are not inundated with requests for participation. The school is also an ideal venue for health promotion and education about cardiovascular risk. Most schools have curriculum related well to health, health promotion and heart health. They also have teachers of science, health, sociology and physical education where content about cardiovascular health and risks are well suited.

Clinics and doctors' offices can also be viewed as potential places to conduct research. The only routine health intervention occurrences may be around immunization times that take place in teen years in some cultures.

\section{Interventions, programs and strategies to reduce cardiovascular disease and risk factors in adolescents}

\subsection{Intervention approaches to reduce cardiovascular risk factors in adolescents}

Conducting primary prevention of CVD, beginning in early childhood and sustained through adolescence has been well supported by the extensive evidence from epidemiological, clinical, and laboratory studies conducted world-wide and the examples reviewed in this chapter. Approaches to reduce and prevent cardiovascular disease can include primary prevention and health promotion for the general population before CVD occurs; secondary prevention to identify those at risk and provide opportunities for change; and tertiary prevention to identify those with CVD and associated risks such as diabetes and obesity and intervene. Some of the approaches used for adolescent heart health are:

- Education and health promotion strategies that include information on heart health, holistic health and well-being. These strategies can target, individuals, groups and populations.

- Risk awareness programs include overall surveillance data given to the adolescent, family, physician or community to raise awareness to stimulate readiness and change. 
- Risk assessment, testing and screening methods that include testing and monitoring of blood pressure, cholesterol, BMI calculations, waist circumference and physical activity.

- Specific lifestyle behaviour change strategies that may include introducing specific interventions to reduce smoking, increase physical activity, improve nutrition, stop smoking; and reduce overweight and obesity. These approaches involve developing skills and behavioural changes.

- Consultation, treatment and health counseling interventions for those who are identified with cardiovascular risks include retesting, monitoring, consultation, counseling or treatment provided in adolescent friendly environments. These approaches require using effective referral, counseling, monitoring and treatment approaches that work best with adolescents.

- Comprehensive, overall adolescent heart health programs that include all aspects: health promotion; risk awareness and education; assessment, testing and screening; consultation, referral, counseling and treatment.

It is generally believed that awareness is the first step in an individual, a community or a society to be able to take action and adopt health promoting behaviours, especially with modifiable risk factors. Studies show mixed results on the connection between knowledge of $\mathrm{CV}$ risk factors and the adoption of healthier behaviours. The Canadian Heart Health Initiative, 1988-2005 reported that Canadians have a low awareness of the causes of CVD. A full $30 \%$ could not even name one of the major risks factors for heart disease (smoking, high blood pressure, elevated blood cholesterol, sedentary lifestyle, diabetes).

Smalley (2004) in a United States study assessed the attitudes of adolescents regarding CVD risk factors and determined their potential influence on reported health habits including exercise, smoking diet and BMI. This study included 141 males and 207 female adolescents at 2 clinic sites serving mostly Medicaid or uninsured populations using self-report scales. The majority of participants agreed that obesity, smoking and high fat diets may lead to heart disease. In the sample, $50 \%$ exercised 3 times or less a week. The occurrence of obesity was higher than national averages; smokers were 1.9 times as likely to be overweight or obese; and if they had parents or grandparents with a history of heart attacks, the adolescents were 2.7 times as likely to smoke. They concluded that adolescents possess knowledge of $\mathrm{CV}$ risk factors as reflected in their attitude assessments; however, their lifestyle choices contradict these beliefs.

\subsection{Sample adolescent cardiovascular risk projects: Research, assessment, identification, education and intervention}

This chapter has reviewed many research projects and initiatives related to aspects of cardiovascular risk in adolescents. Along with the research descriptions the health promotion, awareness and prevention interventions have been described that were part of the study or evaluation. Many programs involved specific or combined lifestyle behaviour change interventions or risk factor testing. Few programs were comprehensive in nature and included: family history and engagement, assessment and testing of risk factors; education and health promotion; and a defined or researched process for referral, follow-up, assessment and treatment with adolescents. Few were specifically designed for adolescents with both a research and comprehensive educational assessment or referral intervention component. Two comprehensive programs with many of the components will be described 
here: a Canadian overall heart health program and a Dutch school program for the prevention of obesity.

\subsubsection{Niagara Schools Healthy Heart Program (NSHHP)}

The Niagara Schools Healthy Heart Program (NSHHP) in Ontario, Canada is a primary prevention program developed for adolescents continuing over 24 years since 1987 by Heart Niagara, a community organization dedicated to the prevention of CVD and heart health education for all age groups. The adolescent program initially was delivered in collaboration with public health school nurses and teachers with each respective high school. In more recent years, it was delivered by a nurse practitioner and health promotion staff of Heart Niagara along with teachers. Research collaboration over the twenty four years has developed between Heart Niagara and the Brock University Nursing Department from 2002 to present. In 2007, the Division of Cardiology of the Labatt Family Heart Center, Department of Pediatrics, and The Hospital for Sick Children in Toronto also became a research partner.

The NSHHP is a comprehensive heart health program offered to all grade nine students enrolled in a physical education course in any of the 30+ secondary schools in Niagara Region, Ontario, Canada. The Program is a comprehensive heart health initiative targeted at adolescents who are mostly $14-15$ years of age. It has the following components:

- Family history and involvement ... the parent/guardian is engaged to review the program and sign permission for student involvement in the research, education and screening aspects of the program. The student and the parent/guardian also complete a questionnaire on Family History of Cardiovascular Disease that is sent home with the students. The family is encouraged to discuss the health history, particularly of cardiovascular disease in parents, siblings and grandparents, to begin the awareness process. If the student is identified through the screening to warrant a suggested referral for follow-up to their physician, parents are informed and are often engaged in this part of the process and dialogue.

- Screening assessment and testing ... Height and weight are measured to calculate Body Mass Index (BMI). Blood pressure and non-fasting total cholesterol screening is also conducted by a registered nurse at the school site. If some of the testing results are over the standards established, students are referred to their primary health care provider/physician for follow-up and a letter goes to the student, parent/guardian and physician.

- $\quad$ Lifestyle assessment ... Students complete a self-rated, paper and pen survey which includes questions about dietary intake, caffeine intake, level of physical activity, sleeping habits, smoking, and other lifestyle behaviours. This data forms part of the student's heart awareness of their individual lifestyle risk factors and is collected for research purposes to trend heart risk factors for this age group.

- Health promotion educational presentations ... A one hour heart health promotion presentation is given in the classroom by Heart Niagara staff or volunteers along with teachers in the classroom. Students are taught about heart disease risk factors, and that heart disease begins in adolescence. They are also taught that heart disease can be prevented by knowledge of family history, awareness of personal health profiles and behaviours and adopting healthy choices in nutrition, activity and choosing not to smoke. CPR training is also offered by staff and volunteers of $\mathrm{HN}$ for all students in the 
classroom. This part of the program builds the capacity for the community to engage in life saving, beginning early in adolescence.

- Referral and follow up ... Students whose questionnaire or individual assessment indicate any of the following are referred to their family physician to discuss the results: positive family histories; non-fasting total cholesterol above $95^{\text {th }}$ percentile or nonfasting total cholesterol/high density lipoprotein ratios above 5.71; body mass index above $95^{\text {th }}$ percentile; smokers who request help with cessation. Students and parents are informed that while the assessment is not definitive, they should follow-up with their family doctor or paediatrician. A diagrammatic referral process has been outlined. This program has developed several helpful process charts related to referral and follow-up.

Since the inception of the NSHHP in 1987, the questionnaires and process steps have been revised, improved and updated for effectiveness and enhanced awareness research capacities. Detailed descriptions of the program and protocols have been developed; training has been conducted for those doing the screening and testing to ensure consistency in equipment and measurements; and the use of standardized criteria for blood pressure and non-fasting total cholesterol readings have been implemented. Alogorithms have been developed regarding the referral and follow-up process and alogorithms have been developed to assist physicians regarding assessment and treatment of paediatric lipids; assessment, diagnosis and treatment of paediatric hypertension; assessment and treatment of overweight and obesity; and smoking cessation (Heart Niagara, 2007).

\subsubsection{The Dutch Obesity Intervention in Teenagers (NRG-DOiT) (Singh et al. 2006)}

This initiative applied the Intervention Mapping (IM) protocol in the systematic development, implementation and evaluation of their school-based intervention program aimed at the prevention of excessive weight gain. The program focused on the reduction of the consumption of sugar-sweetened beverages; reduction of energy intake derives from snacks; decreased levels of sedentary behavior; and increased levels of physical activity (i. e. active transport behaviour and sports participation). Steps in the development and implementation process of bringing this program to teens are well described and outlined.

\section{Conclusion}

\subsection{Epidemiological and surveillance data should be collected to trend and monitor $\mathrm{CV}$ risk factors at a population health level for planning purposes}

Global and national research surveillance and population health data about CV risk factors and their associations have been collected in the last three decades. Each nation has developed research tools and methodology for this task. More sharing of research methods and findings is occurring to improve the research and to improve health. Some examples will be presented here. The lack of comparable data and consistent criteria limits crosscountry and cross national research to some degree has been limited up to now, but the capacity to collaborate in interdisciplinary and global research on adolescent health holds exciting potential. Initiatives regarding the prevention of disease for different age population, including adolescents have been developed and many of them are being evaluated for their impact on reducing specific or overall risks. We are beginning to have 
some best practices developing to improve our practice of health promotion and risk prevention with adolescents.

World-wide, the INTERHEART (Yusef et al., 2004) project of the World Health organization is a population health based surveillance approach operating in 52 countries world-wide to monitor changes in youth health and reporting on global, national and regional trends regarding many of the $\mathrm{CV}$ risk factors. This project uses a common methodology and survey tool and target ages with some variations in how the research samples are selected in each country.

In the United States, there are several large, ongoing long-term studies beginning in childhood and extending through adolescence, young adulthood and to middle age. The Framington Offspring study and the Bogalusa Heart Study (BHS) examine the predisposing characteristics, risk factors, and lifestyle behaviours related to future CVD, hypertension, and diabetes. A strong and highly significant correlation has been found between the acceleration and severity of coronary and aorta atherosclerosis and the increasing numbers of risk factors. Studies show that early onset of smoking, alcohol use, poor diets, and poor lifestyles are linked with clinical cardiovascular risk and beginning cardiovascular disease (Berenson et al., 2010, p. 272).

The Pathologic Determinants of Arteriosclerosis in Youth (PDAY) has shown a strong correlation between risk factors and actual lesions in the CV system (Wissler et al, 1998).

The American Heart Association's report from the Children's Heart Health Conference Improving Children's Heart Health (1994 in Chicago) focused on public health, lifestyle and behaviour and outlined recommendations in the areas of physical activity, nutrition and tobacco. The AHA (1997) statement on integrated cardiovascular health promotion in children addressed the health professional's role in adolescent heart health.

In Canada, the Canadian Community Health Survey is conducted every 4 years with the population over 15 years of age and the census is conducted every 4 years with those over 18 years of age. Data on health and lifestyle behaviours are reported for the nation, the province and the region that can be used in planning.

Risk factors change throughout age and maturation; they are different by race and gender. "In childhood just as in adulthood - risk factors ocurr in a constellation - a condition called metabolic syndrome" (Berenson et al., 2010, p. 5). Obesity and insulin are driving factors of the myriad variables associated with body fatness. Long-term studies show that obesity precedes hyperinsulimemia/ insulin resistance. Obesity in childhood is the most consistent factor predictive of adult CV system changes - cardiac enlargement and evidence of vascular stiffness (Toprak et al., 2008 in Berenson, 2010).

\subsection{Education and health promotion interventions for adolescents should be integrated into school-based, community-based and family-based health promotion approaches}

A call to action is required for societies, communities, schools, families, physicians and individuals armed with information to take positive action for health changes. With current, reliable, valid and comparable data and evidence, we can better identify when and where to intervene and the specific and effective nature of the intervention: how it can be specified, 
shaped, targeted and evaluated. If we believe that interventions can change risk factors and therefore, reduce cardiovascular disease, then research on adolescent heart health should have several important health awareness target groups for overall effectiveness outcomes:

- Awareness for parents to understand the power of history, modeling and their health examples to continue to improve the health of family units as a social and influential target of improved lifestyle behaviours.

- Awareness for health practitioners armed with evidence should lead us to how to better promote health through our programs and individual efforts working directly with adolescents. Adolescent friendly and remove barriers ..

- Awareness for educators to play an increased role in health teaching, education and identification of $\mathrm{CV}$ risks.

- Increased awareness for the adolescent of their heart risk factors could provide an opportune time to make positive personal changes for their health such as exercising or stopping smoking.

- Awareness for researchers that there is some urgency to conduct reliable and valid research on adolescent cardiovascular health and risks and to make their results available in knowledge transfer approaches to individuals, the public and health planners and policy makers.

- Awareness for health planners, policy makers and decision makers of the importance of health promotion and disease prevention research and education that needs to be adopted on a large-scale and at an earlier age that is well planned, funded, delivered and evaluated.

Two sample international research reviews have been conducted to assess and guide intervention development, implementation and evaluation. Flynn et al. (2006) did a synthesis of the evidence related to reducing obesity and related chronic disease risk in children and youth and described best practices and recommendations that resulted from the review. They reviewed 982 reports, of which 500 were selected for critical appraisal. Appraisal scores on program development and evaluation were used. As a result of the review, they identified best practices and made recommendations to guide researchers, educators and care providers for increased effectiveness, This review process can be applied well in adolescent cardiovascular risk research and intervention to identify best practices.

Doak et al. (2006) conducted a review of interventions and programs for the prevention of overweight and obesity in children; one of the major CV risk factors, They assessed existing interventions qualitatively and quantitatively. The review focused on school-based programs with a quantitative evaluation using athropometric outcomes and those that intervene on diet and activity related behaviours. They found that $67 \%$ (17 of 25) were "effective" based on a statistically significant reductions in BMI, as well as skinfold measures. Physical activities in schools and the reduction of television viewing are two examples of interventions that were particularly effective. They observed that programs for sub-groups (such as immigrants) are not particularly well developed or effective This study has relevance for how to conduct a systematic review of interventions for other $\mathrm{CV}$ risk factors.

In 2004, the American Heart Association (AHA) issued a statement on cardiovascular health promotion in the schools. They reviewed the evidence regarding the efficacy and potential of such an approach. The collective results of school-based recommendations outlined in the AHA's Guide for improving cardiovascular health at the community level indicated that schools 
are an important component of a population-based health promotion and risk reduction approach. A majority of the school-based studies reviewed in this chapter are from school initiatives and the systematic reviews prepared by Resnicow et al (1996) and Meininger (2000) supported this direction. The AHA issued specific recommendations related to heart health education and health behaviours including goals and recommendations for school policies, and school and community linkages.

In Australia, the Report on health goals and targets for Australian children and youth (1992 in Stanton, Willis \& Balanda, 2000) was to reduce the frequency of preventable premature mortality; to reduce the impact of disability (new or developed); to reduce the incidence of vaccine-preventable disease; to reduce the impact on conditions occurring in adulthood which have their origins in early manifestations in childhood or adolescence and; enhance family and social functioning (p. 182). Better health outcomes for Australians (CDHSH, 1994) is a document addressing the issue of youth health with a particular focus on cardiovascular disease, cancer, mental health and injury.

The report from the American Heart Association's Children's Heart Health Conference Improving Children's Heart Health that had a focus on public health, lifestyle and behaviour developed recommendations in the areas of physical activity, nutrition and tobacco. An AHA (1997) statement on integrated cardiovascular health promotion in children oultined the health professional's role in adolescent heart health.

\subsection{Treatment and clinical interventions}

To merely identify those adolescents at risk is not enough. There also needs to be well trained primary care providers who are aware and knowledgeable about heart disease and skilled at working with adolescents, families, schools and communities in motivation, consultation and delivering adolescent friendly care. Laudenbach (2004) suggests we also offer family strengths-based interventions to help the entire family to get fit and heart healthy. The same is true of adopting a strengths-based approach where health care providers work with the community to build the capacity for health for all. Building a wider healthy community with good eating and physical activity habits would also positively affect adolescent cardiovascular health.

Treatment of cardiovascular risk factors is considered a challenging and evolving aspect of preventive medicine, especially with adolescents and young adults. Lule et al. (2006) suggest that efforts to improve the health of young people may be even more complex and challenging than for other age groups because many of their health issues are behaviourbased and actual symptoms of CVD may not be evident, or seen as serious yet. Walker et al. (2002) found few published reports of screening and health promotion in family practice settings and Walker and Townsend (1998) reported that according to 200 health care providers in 200 U. S. cities, youth are at a point when health intervention could make a difference, but that preventive, primary reproductive, and behavioural health care is not well matched to adolescent needs and preferences. The Canadian Task Force on Preventive Health care (2000) suggested that an adolescent friendly atmosphere is needed and teens reported that issues of confidentiality and access to telephone and good written information is needed. Access to computer health information and dialogue has become important. The 
WHO (2002) described the features of adolescent friendly health services and called for appropriate changes to create them

\subsection{A comprehensive model}

The evidence is strong that cardiovascular risk factors begin and can be identified in childhood and adolescence that influence the development of CVD in adulthood. Evidence is growing that some effective best practices are developing about both individual approaches and holistic approaches in health promotion, early screening, and health care interventions that may have some positive potential for prevention and intervention. Interdisciplinary and interprofessional teams of researchers, clinicians, educators, parents and care providers are working together on this health issue and informing each other of their outcomes. Programs and policies are emerging from the information to guide practice to improve health and reduce risk. The time to act is now.

A comprehensive model for cardiovascular risk assessment, identification, education, health promotion, referral and treatment for adolescents (Kilty \&Prentice, 2011)

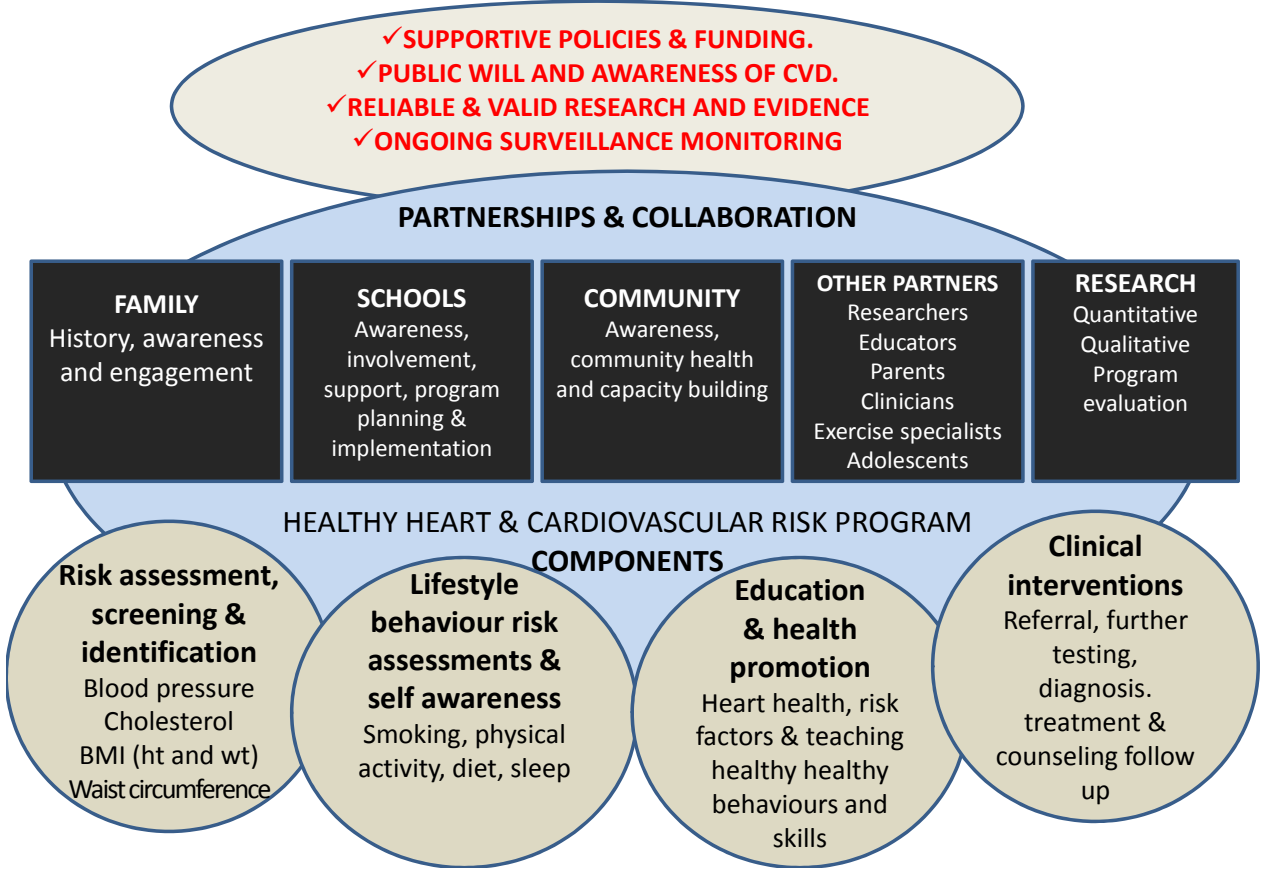

"Unlike treatment for problems that produce symptoms, preventive medicine is optional"

(Kamerow, 2008, p. 23)

"Knowing is not enough; we must apply. Willing is not enough; we must do."

Goethe 


\section{References}

Aatola, H., Koivistoinen, T., Hutri-Kahonen, N., Juonala, M. et al. (2010). Lifetime fruit and vegetable consumption and arterial pulse wave velocity in adulthood: The cardiovascular risk in young Finns study. Circulation, 122, 2521-2528.

Adler, N. E., \& Newman, K. (2002). Socioeconomic disparities in health: Pathways and policies. Health Affairs, 21, 60-76.

Allen, M., \& Warner, M. (2002). A developmental model of health and nursing. Journal of Family Nursing, 8(2), 96-135.

American Heart Association (2007). Risk factors and coronary heart disease. Retrieved May 31, 2007 from http:/ / www.americanheart.org/presneter.jhtml?indentifier=4726.

Andersen, R. T., Sorlie, P., Backlund, E., Johnson, N., \& Kaplan, G. A. (1997). Mortality effects of community socioeconomic status. Epidemiology, 8, 42-47.

Andersen, L. B., Wedderkopp, N., Hansen, H. S. Cooper, A. R., \& Froberg, K. (2003). Biological cardiovascular risk factors in Danish children and adolescents: The European Youth Heart Study. Preventive Medicine, 37(4), 363-367.

Andersen, R. C., Crespo, C. S., Bartlett, S. J., \& Pratt, M. (1998). Relationship of physical activity and television watching with body weight and level of fatness in children. Journal of the American Medical Association, 179, 938-942.

Appel, S. J., Harrell, J. S., 7Deng, S. (2002). Racial and socioeconomic differences in risk factors for cardiovascular disease among southern rural women. Nursing Research, 51, 140-

Barker, J. G., Bolitho, F., \& Bertrand, L. D. (1999). The predictors of adolescent smoking. Journal of Social Service Research, 26(1), 51-66.

Berenson, G. S., S. R., Srinivasan, Fernandez, C., \& Xu, J. (2010). Can adult cardiologists play a role in the prevention of heart disease beginning in childhood? MDCVI, 4, 4-9.

Berkey, C. S., Rockett, R. H., Gillman, M. W. \& Colditz, G. A. (2003). One-year changes in activity and inactivity among 10-15 year old boys and girls: Relationship to body mass index. Pediatrics, 111, 836-843.

Bhattacharjee, R., Kheirandish-Gozal, Pillar, G., \& Gozal, D. (2009). Cardiovascular complications of sleep apnea syndrome: Evidence from children, Progress in Cardiovascular Diseases, 51 (5), 416-433.

Bond, L. A., \& Compas, B. E. (Eds.). (1989). Primary prevention and promotion in schools. Beverley Hills, CA: Sage.

Bouziotas, C., \& Koutedakis, Y. (2003). A three year study of coronary heart disease risk factors in Greek adolescents. Pediatric Exercise Science, 15(1), 9-18.

Brotons, C., Ribera, A., Perich, R. M., Abrodos, D., Magana, P., Pablo, S., et al. (1998). Worldwide distribution of blood lipids and lipoproteins in childhood and adolescence: a review study. Atherosclerosis, 139(1), 1-9.

Buchan, D. S., Ollis, S., Young, J. D. Thomas, N. E., Cooper, S. M., Tong, T. K., Nie, J., Malina, R. M., \& Baker, J. S. (2011). The effects of time and intensity of exercise on novel and established markers of CVD in adolescent youth. American Journal of Human Biology, 23(4), 517-526.

Canadian Community Health Survey (2004/2005; 2007/2008). Statistics Canada.

Canadian Heart and Stroke Foundation (2010) A perfect storm of heart disease looming on our horizon. Annual Report. Canadian Heart Health Initiative 1988-2003 
Cappuccio, F. P., Cooper, D., D’Elia, L. et al. (2011). Sleep duration predicts cardiovascular outcomes: A systematic review and meta-analysis of prospective studies. European Heart Journal, 32(12), 1484-1492.

Chmiel-Polec, Z., \& Cybulska, J. (2008). Smoking and other risk factors of cardiovascular disease, connected with arteriosclerosis among youth. Przegl Lek, 65, 437-445.

Chobanian, A.V., Bakris, G.L., Black, H.R., Cushman, W.C., Green, L.A.,\& Izzo Jr., J. L. (2003). National High Blood Pressure Education Program Coordinating Committee. JAMA, 289 (19), 2560-2572.

Chronic Disease Genomics Project. Cardiovascular disease and family history. Minnesota Department of Health.

http://www.health.mn.us/divs/hpcd/genomics/resources/fs/cv.html Retrieved May, 2007.

Cole, T.J., Bellizzi, M.C. Flegal, Flegal, K.M., \& Dietz, W.H. ( 2000). Establishing a standard definition for child overweight and obesity worldwide international survey. BMJ, 320, 1-6.

Colhoun, H. M., Hemingway, H., \& Poulter, N. R. (1998). Socio-economic status and blood pressure: an overview analysis. Hypertension, 12, 91-110.

Cox, A.M., McKevitt, C., Rudd, A. G., \& Wolfe, C. D. A. (2006). Socioeconomic status and strole. Lancet Neurology, 5, 181-188.

Daniels, S.R., Greer, F.R., and the Committee on Nutrition. (2008). Lipid Screening and cardiovascular health in childhood. Pediatrics, 122 (1), 198-208.

Daniels, S. R., Jacobson, M. S., \& McCrindle, B. W., Eckel, R. H., \& Sanner, B. M., (2009). American Heart Association childhood obesity research summit: Executive summary. Circulation, 119, 2114-2123.

Dietz, L. J., \& Matthews, K. A. (2011). Depressive Symptoms and subclinical markers of cardiovascular disease in adolescents. Journal of Adolescent Health, 48, 579-584.

Doak, C. M., Visscher, L. S., Renders, C. M. \& Seidell, J. C. (2006). The prevention of overweight and obesity in children: A review of interventions and programmes. International Life Sciences Institute, 7, 111-136.

dos Santos Cavalcanti, C. B., de Barros, M. V., Meneses, A. L., Santos, C. M., Azevedo, M. P., \& Guimaraes, J. (2010). Abdominal obesity in adolescents: Prevalenece and association with physical activity and eating habits. Arq. Bras. Cardiology, 94 (3),

Du, Y., Rosner, B. M., Knopf, H., Schwarz, S., Doren, M., \& Scheidt-Nave, C. (2011). Hormonal contraceptive use among adolescent girls in Germany in relation to health behavior and biological cardiovascular risk factors. Journal of Adolescent Health, 48, 331-337.

Erikson, E. H. (1950). Childhood and society. New York, NY: Norton (1950); Triad/Paladin (1977), p.242.

Eversen, S. A., Maty, S. C., Lynch, J. W., \& Kaplan, G. A. (2002). Epidemiological evidence for the relation between socioeconomic status and depression, obesity and diabetes. Journal Psychosomatic Research, 53, 891-895.

Ebbeling, C. B., Pawlak, D. B., \& Ludwig, D. S. (2002). Childhood obesity: Public-health crisis, common sense cure. Lancet, 360, 473-482.

Flegal, K.M. \& Ogden, C.L. (2011). Childhood obesity: Are we all speaking the same language? Advances in Nutrition, 2, 1595-1665. 
Flouris, A. D., Canham, C. H., Faught, B. E., \& Klentrou, P. (2007). Prevalence of cardiovascular disease risk in Ontario adolescents. Arch. Dis. Child, 92, 521-523.

Flynn, M. A., McNeil, D. A., Maloff, B., Mutasingwa, D., Wu, M., Ford, C., \& Tough, S. C. (2006). Reducing obesity and related chronic disease risk in children and youth: A synthesis of evidence with "best practice" recommendations. The International Association for the Study of Obesity, 7, 7-66.

Ford-Gilboe, M. (2002). Development and testing a measure of family health promotion behavior: The Health Options Scale. Unpublished manuscript, Wayne State University, Detroit, Michigan.

Ford-Gilboe, M. (1997). Family strengths, motivation, and resources as predictors of health promotion in single-parent, and two-parent families. Research in Nursing and Health, 20, 205-217.

Ford, E.S., Li, C., Zhao, G., \& Mokdad, A. H. ( 2009). Concentrations of low-density lipoprotein cholesterol and total cholesterol among children and adolescents in the United States. Circulation, 119, 1108-1115.

Freedman, D. S., Khan, L., Dietz, W. H., Srinivasan, S. R., \& Berenson, G. S. (2001).Relationship of childhood obesity to coronary heart disuse risk factors in adulthood: The Bogalus Heart Study. Pediatrics, 108(3), 712-718.

Gidding, S.S., Deckelbaum, R. J., Strong, W., \& Moller, J. H. (1995). Improving children's heart health: A report from the American Heart Association's Children's Heart Health Conference. (1995). The Journal of School Health, 65(4), 129-132.

Gordon-Larsen, P., McMurray, R. G., \& Popkin, B. M. Determinants of adolescent physical activity and inactivity patterns, Pediatrics, 105(6).

Gortmaker,S. L., Must, A., Sobol, A. M., Peterson, K., Colditz, G. A. \& Dietz, W. H. (1996). Television viewing as a cause of increasing obesity among children in the United States, 1986-1990. Arch Pediatric Adolescent Medicine, 150, 356-362.

Gozal, D., Kheirandish-Gozal,L.,Serpero,L.D., Sans Capdevila,O., \& Dayyat, E. (2007). Obstructive sleep apnea and endothelial function in school-aged nonobese children: Effect of adenotonsillectomy, Circulation, 116, 2307-2314.

Grotto, I., Huerta, M., \& Sharbi, Y. (2008). Hypertension and socioeconomic status. Curr. Opin. Cardio., 23, 335-339.

Greenlund, K. J., Johnson, C., Wattigney, W., Bao, W., Webber, L. S., \& Berenson, G. S. (1996). Trends in cigarette smoking among children in a southern community 1976-1994: The Bogalusa Heart Study. American Journal of Pediatric Obesity, 89(8), 1345-1348.

Gutin, B., \& Owens, S. (1999). Role of exercise interventions in improving body fat distribution and risk profile in children. American Journal of Human Biology, 11(2), 237-247.

Hayman, L. L., Williams, C. L., Daniels, S. R., Steinberger,J., Paridon, S., Dennison, B. A., \& McCrindle, B. W. (2004). Cardiovascular health promotion in the schools: a statement for health and education professionals and child health advocates from the Committee on Atherosclerosis, hypertension, and obesity in Youth (AHOY) of the Council on Cardiovascular Disease in the Young. Circulation,110(5), 2266-2275.

Health Canada (2011) Canada Food Guide. Ottawa, ON.

Health Canada. (2011). Trends in the health of Canadian youth: Youth health behaviours in schoolaged children. Ottawa, ON. 
Heart Niagara. (2008). Identifying and managing adolescent cardiovascular risk. Niagara Falls, ON: Heart Niagara.

Hemmings, S., Connor, A., Maffulli, N., \& Morrissey, D. (2011). Cardiovascular disease risk factors in adolescent British South Asians and whites: A pilot study. Postgraduate Medicine, The Royal London Hospital, 123(2), 104-111.

Hennekens \& Bering (1987) p. 3

Huxley, R., Mendis, S., Zheleznyakov, E., Reddy, S. \& Chan, C. (2010). Body mass index, waist circumference and waist: hip ratio as predictors of cardiovascular risk- a review of the literature. European Journal of Clinical Nutrition, 64, 16-22.

Institute of Medicine. (2002/2005). Dietary reference intakes for energy, carbohydrates, fiber, fat, fatty acids, cholesterol, protein, and amino acids. Washington, DC: The National Academies Press.

Kamerow, D. (2008). Should we screen for and treat childhood dyslipidaemia? BMJ, 337, a886.

Kaplan, G. A., \& Keil, J. E. (1993). Socioeconomic factors and cardiovascular disease: A review of the literature. Circulation, 88, 1973-1998.

Kavey, R. W. (2010). How sweet it is: Sugar-sweetened beverage consumption, obesity, and cardiovascular risk in childhhood. Journal of the American Dietetic Association. 110(10), 1456-1460.

Kilty, H. \& Prentice, D. (2010) Adolescent cardiovascular risk factors: A follow-up study of nurse referrals to physicians. Clinical Nursing Research Journal, 19 (1), 6-20.

King, A. J. C. \& Coles, B. (1992). The health of Canadian Youth. Health and Welfare Canada, Ottawa, ON.

Krebs, N. F., Baker, R. D., Greer, F. R., Hayman, M. B., Jaksic, T., et al. (2003). Policy Statement: Prevention of Pediatric Overweight and Obesity Prevention Committee on Nutrition. Pediatrics, 112(2), 424-435.

Krishnan, S., Copeland, K. C., Bright, B. C., Gardner, A. W., Blackett, P. R., \& Fields, D. A. (2011). Impact of type 1 diabetes and body weight status on cardiovascular risk factors in adolescent children. The Journal of Clinical Hypertension, 13 (5), 351- 356.

Laing, S.P., Swerdlow, A. J., \& Slater, S.D. et al. (1999). The British Diabetic Association and cohort study, II: Cause-specific mortality in patients with insulin-treated diabetes mellitus. Diabetic Medicine, 16, 466-471.

Libby, P., Nathan, D. M., \& Abraham, K. et al. (2005). Report of the National Heart, Lung and blood Institute - National Institute of Digestive and Kidney Diseases Working Group on Cardiovascular Complications of Type 1 Diabetes Mellitus. Circulation, 111, 3489-3493. .

Laudenbach, L., \& Ford-Gilboe, M. (2004). Psychometric testing of health options scale with adolescents. Journal of Family Nursing, 10(1), 121-138.

Lee, C.M., Huxley, R., Wildman, R.P., \& Woodward, M. (2008). Indices of abdominal obesity are better discriminators of cardiovascular risk factor than BMI: a meta analysis. Journal of Clinical Epidemiology 61, 646-653.

Lobelo, F., Pate, R. R., Dowda, M., Liese. A. D., \& Daniles, S. R. (2010). Cardiorespiratory fitness and clustered cardiovascular disease risk in U.S. adolescents. Journal of Adolescent Health, 47, 352-359. 
Lule, E., Rosen, J. E., Singh, S., Knowles, J. C., \& Behrman, J. R. (2006). Adolescent health programs. In disease control priorities in developing countries.New York: Oxford University.

Luma, G. B. \& Spiotta, R. T. (2006). Hypertension in children and adolescents. American Family Physician, 73 (9), 1558-1566.

Ma, G.S., Ji, C.Y., Ma, J., Mi, J., Sung, R.Y., Xiong, F., Yan, W.L., Hu, X.Q., Li, Y.P., Du, S.M., Fang, H., Y., \& Jiang, J.,X. (2010). Waist circumference reference values for screening cardiovascular risk factors in Chinese children and adolescents. Biomedical and Environmental Sciences 23, 21-31.

Maggio, A. B. R., Aggoun, Y., Martin, X. E., Marchand, L. M., Beghetti, M., \& Farpour-Lambert, N. J. (2010). Long-termfollow-up of cardiovascular risk factors after exercise training in obese children. International Journal of Pediatric Obesity, 6(2), 603-610.

Manios, Y., Magkos, F., Christakis, G. \& Kafatos, A. G. (2005). Twenty-year dynamics in adiposity and blood lipids of Greek children: Regional differences in Crete persist. Acta Paediatric, 94(7), 859-865.

Mathers, C. D. (1998). Health differentials among adult Australians aged 25-64. Canberra: Australian Institute of Health and Welfare. Health Series WO-1.

McCrindle, B. W. (2000). Screening and management of hyperlipidemia in children. Pediatric Annals, 29 (8), 500-508.

McCrindle, B., Manlhiot, C., Millar, K., Gibson, D., Stearne, K., Kilty, H., Prentice, D., Wong, H., Chatal, N \& Stafford, D. (2010). Population trends towards increasing cardiovascular risk factors in Canadian adolescents. The Journal of Pediatrics, 157 (5), 837-843.

McCusker, M. E., Yoon, P. W., Gwinn, M., Malarcher, A. M., Neff, L., \& Khoury, M. J. (2004). Family history of heart disease and cardiovascular disease risk-reducing behaviors. Genetic Medicine, 6(3), 153-158.

McGill, H.C., McMahan, C. A., Zieskie, Malcolm, G. T. Oalmann, M. C. \& Strong, J. P. (1997). Effects of serum lipoproteins and smoking on arthrosclerosis in young men and women. The PDAY Research Group. Pathobiological determinants of atherosclerosis in youth. Arterioscler, Throm. Vasc Bio, 17(1), 95-106.

Meininger, J. C. (2000). School-based interventions for primary prevention of cardiovascular disease: Evidence of effect for minority populations. American Review of Nursing Research, 18, 219-244.

Michos,E. D., Nasir, K., Rumberger, J. A., Vasamreddy, V., Braunstein, J. B., Budoff, M. J., \& Blumenthal, R. S. (2004). Relation of family history of premature coronary heart disease and metabolic risk factors to risk of coronary arterial calcium in asymptomatic subjects. The American Journal of Cardiology, 95(5), 655-657.

Murabito, J. M., Nam, B. H., D'Agostino, S. B. Jr., Lloyd-Jones, D. M., O’Donnell, C. J., \& Wilson, P. W. (2004). Accuracy of offspring reports of parental cardiovascular disease history: The Framingham Offspring Study. Annuals of Internal Medicine, 140, 434-440.

Nakumura, T., Tsubono,Y., Kameda-Takemura, K., Funahashi, T., Yamashita et al. (2001). Magnitude of sustained multiple risk factors for ischemic heart disease in Japanese employees: A case-control study. Japanese Circ Journal, 65, 11-17.

Nasir, K., Michos, E. D., Rumberger, J. B., Braunstein, W. S., Post, Budoff, M. J., \& Blumenthal, R. S.(2004). Coronary artery calcification and family history of 
premature coronary heart disease: sibling history is more strongly associated than parental history. Circulation, 110, 2150-2156.

National High Blood Pressure Education Program Working Group on High Blood Pressure in Children and Adolescents (2004). The Fourth Report on the diagnosis, evaluation, and treatment of high blood pressure in children and adolescents. Pediatrics, 114, 555-576.

Newman, W.P., Freedman, D. S. Voors, A. W. et al., (1986) Relation of serum lipoprotein levels and systolic blood pressure to early atherosclerosis: The Bogalusa Heart Study. New England Journal of Medicine, 314(3), 138-144.

O'Donnell, C. J. (2004). Family history, subclinical atherosclerosis, and coronary heart disease risk: Barriers and opportunities for the use of family history information in risk prediction and prevention. Circulation, Journal of the American Heart Association, 110, 2074-2076.

Ogden, C. L., Carroll, M. D., Curtin, L. R., Lamb, M. M.\& Flegal, K. M. (2010). Prevalence of high body mass index in US children and adolescents. JAMA, 303, 242-249.

Ogden, C. L., Flegal, K. M., Carroll, M. D., \& Johnson, C. L. (2002). Prevalence trends in overweight among US children and adolescents 1999-2000. Journal of the American Medical Association, 288, 1728-1732.

Onkamo,P.,Vaananen, P., Karvonen, M., \& Tuomilehto, J. (1999). Worldwide increase in incidence of Type 1 diabetes - the analysis of data on published incidence trends. Diabetologia, 43(10), 1334-1336.

Paradis, G., Lambert, M., O'Laughlin, J., et al. (2003). The Quebec child and adolescent health and social survey: Design and methods of a cardiovascular risk factor survey for youth. Canadian Journal of Cardiology, 19, 523-531.

Park, J. W., Yun, J. E., Park, T., Cho, E., Jee, S. H. Jang, Y., Beaty, T. H., Samet, \& J. M. (2007). Family history of diabetes and risk of atherosclerosis cardiovascular disease in Korean men and women. Atherosclerosis, 197(1), 224-231.

Pollitt, R. A., Rose, K. M. \& Kaufman, J. S. (2005). Evaluating the evidence for models of the life course socioeconomic factors and cardiovascular outcomes: A systematic review. BMC Public Health, 5, 7.

Prentice, D., Kilty, H. L., Stearne, K. \& Dobbin, S. (2008). Prevalence of cardiovascular risk factors in grade nine students. The Canadian Journal of Cardiovascular Nursing 18(3), 12-16.

Prentice, D. Kilty, H., Stearne, K., \& Dobbin, S. (2006). An adolescent healthy heart program: A three year review. Unpublished manuscript.

Rafraf, M., Gargari, B. P., \& Safaiyan, A. (2010). Prevalence of prehypertension and hypertension among adolescent high school girls in Tabriz, Iran. Food and Nutrition Bulletin, 31(3), 461-465.

Raj, M., \& Kumar, K. (2010). Obesity in children and adolescents. India Journal of Medical Research, 598-607.

Reed, K. E., Warburton, D. E. R., \& McKay, H. A. (2007). Determining cardiovascular disease risk in elementary school children: Developing a healthy heart score. Journal of Sports Science and Medicine, 6, 142-148.

Reedy, J., \& Krebs-Smith, S. M. (2010). Dietary sources of energy, solid fats, and added sugars among children and adolescents in the United States. Journal of the American Dietetic Association, 110(10), 1477-1484. 
Resnico, K., Baranawski, T., Ahluwahlia, J. S., \& Braithwaite, R. L. (1999). Cultural sensitivity in public health defined and demystified. Ethnicity and Disease, 9, 10-21. et al. (1996).

Robinson,T. N. (1999).Reducing children's television viewing to prevent obesity: A randomized controlled trail. JAMA, 282, 1561-1567.

Schreier, H. M. C., \& Chen, E. (2010). Socioeconomic status in one's childhood predict offspring cardiovascular risk. Brain, Behaviour, and Immunity, 24, 1324-1331.

Shuener, M. T. (2004). Clinical application of genetic risk assessment strategies for coronary artery disease: genotypes. Primary Care, 34, 711-737.

Singh, A. S., Chin, M. J. M., Paw, A., Kremmers, S. P. J., Visscher, T. L. S., Brug, J., Mechelen, W. (2006). Design of the Dutch intervention in teenagers (NRG-DOiT): systematic development, implementation and evaluation of a school-based intervention aimed at the prevention of excessive weight gain in adolescents. BMC Public Health, 6, 304.

Sdringola, S., Patel, D., \& Gould, K. L. (2001). High prevalence of myocardial perfusion abnormalities on positron emission tomography in asymptomatic persons with a parent or sibling with coronary artery disease. Circulation, 103, 496-501.

Shakley, D. C., \& Clarke, N. W. (2005). Impact of socio-economic status on bladder cancer outcome. Current Opinion Urology, 15, 328-331.

Shatoor, A. S., Mahfouz, A. A., Khan, M. Y., Daffalla, A. A. Mostafa, O., \& Hammad, R. K. (2010). Cardiovascular risk factors among adolescent secondary school boys in Ahad Rufeida, Southwestern Saudi Arabia. Journal of Tropical Pediatrics, 57(5), 382384.

Shields, M. (2005). Youth smoking. Statistics Canada. Catalogue 82-003. Health Reports, 16 (3).

Siega-Riz, A. M., Popkin, B. M., \& Carson, T. (1998). Trends on breakfast concumption for children in the United States from 1965-1991. American Journal of Clinical Nutrition, 67(4), 7485-7565.

Smith, K. J., Gall, S. L., McNaughton, S. M., Blizzard, L. Dwyer, T., \& Venn, A. J. (2010). American Journal of Clinical Nutrition, 92, 316-1325.

Spicuzza, L. Leonardi, E., \& La Rosa, M. (2009). Pediatric sleep apnea: Early onset of the 'syndrome?" Sleep Medicine Reviews, 13, 111-112.

Stanton, W.R., Willis, M., \& Balanda, K. P. (2000). Development of an instrument for monitoring adolescent health issues. Health Education Research, 15(2), 181-190.

Stary, H. C. (1989). Evolution and progression of atherosclerosis lesions in coronary arteries of children and young adults. Atherosclerosis, 9, 119-132.

Tanusputro, P., Manuel, D. G., Leung, M. et al.(2003). Risk factors for cardiovascular disease in Canada. Canadian Journal of Cardiology, 19, 1249-1269.

Toprak, A., Wand, H., Chen, W., Paul, T., Ruan, I., Srinivasan, S., \& Berenseon, G. (2009). Prehypertension and black-white contrasts in cardiovascular risk in young adults: Bogalus Heart Study. Journal of Hypertension, 27(2), 243-250.

Walker, Z., Townsend, J., Oakey, L., Donovan, C., Smith, H., Hurst, J. et al. (2002). Health promotion for adolescents in primary care: A randomized clinical trial. BMJ, 325, 524-527.

Walker, Z. A., \& Townsend, J. (1998). Promoting adolescent mental health in primary care: A review of the literature. Journal of Adolescence, 21, 621-634. 
Wang, M. Q.,Fitzhugh, E. C., Eddy, J. M., Westerfield, R. C. \& Fu, Q. (1998). Tobacco use among school adolescents: National socio-demographic risk profiles. Journal of Health Education, 29(3), 174-178.

Welsh, J., Sharma, A., Abramson, J. L., Vaccarino, V., Gillespie, M. S., \& Vos, M. B. (2010). Caloric sweetener consumption and dyslipidemia among US adults. JAMA, 303(15), 1490-1497.

Williams, C. L., Hayman, L. L., Daniels, S. R., Robinson, T. M., Steinberger, J., Paridon, S., \& Bizarre, T. (2002). Circulation, 106(9), 1178.

Winter, A., L., de Guia, N. A., Ferrence, R., \& Cohen, J. E. (2002). The relationship between body weight perceptions, weight control behaviours and smoking status in adolescents. Canadian Journal of Public Health, 93(5), 362-365.

Wissler, R. W., Strong, J. P. (1998). Risk factors and progression of atheroscerlosis in youth. PDAY Research Group. Pathological Determinants of athrosclerosis in youth. American Journal of Pathology, 153(4), 1023-1033.

Wong, N. D., Black, H. R., \& Gardin, J. M. (2000). Preventive cardiology: A practical approach. New York, NY: McGraw Hill.

World Health Organization (2011). Waist Circumference and Waist-Hip Ratio: Report of a WHO Expert Consultation. WHO, Geneva, 8-11.

World Health Organization (2009). Global health risks. WHO, Geneva, Switzerland.

World Health Organization. (2008). Inequalities to young people's health: Key findings from the Health Behaviour in School-aged Children (HBSC) 2005/2006 survey. WHO, Geneva, Switzerland,

World Health Organization. (2002).Adolescent friendly health services: An agenda for change. WHO, Geneva. WHO/FCH/CAH/02/14.

World Health Organization. (2005). Preventing chronic diseases: A vital investment. World Global Report. Geneva: World Health Organization.

World Health Organization (1995). Physical status: The use and interpretation of anthropometry. WHO Technical Report Series 854

Yoshinaga, M., Takahashi, H., Shinomiya, M., Miyazaki, A., Kuribayashi, N., \& Ichida, F. (2010). Impact of having one cardiovascular risk factor on other cardiovascular risk factor levels in adolescents. Journal of Atherosclerosis and Thrombosis, 17(11), 11671175.

Yoshinaga, M., Sameshina, K., Tanaka, Y., Arata, M., Wada, A., \& Takahashi, H. (2008). Association between the number of cardiovascular risk factors and each risk factor in elementary school children Circulation, 72, 1594-1597.

Yusuf, S., Reddy, S., Ounpuu, S., \& Anand, S. (2001). Global burden of cardiovascular diseases Part I: General considerations, the epidemiologic transition, risk factors, and impact of urbanization. Circulation, 104, 2746-2753.

Yusuf, S., Hawken, S., Ounpuu, S., Dans, T., Avezum, A., Lanasa, F., McQueen, M., Budaj, A., Pais, P., Varigos, J., \& Lisheng. (2004). Effect of potentially modifiable risk factors associated with myocardial infarction in 52 countries (the INTERHEART study): case-control study. The Lancet, 364, 937-952. 


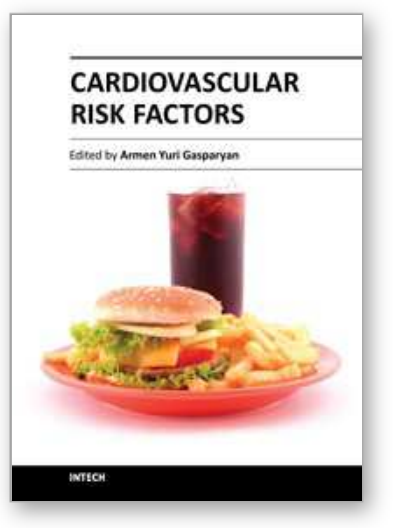

\author{
Cardiovascular Risk Factors \\ Edited by Prof. Armen Gasparyan
}

ISBN 978-953-51-0240-3

Hard cover, 498 pages

Publisher InTech

Published online 14, March, 2012

Published in print edition March, 2012

Cardiovascular risk factors contribute to the development of cardiovascular disease from early life. It is thus crucial to implement preventive strategies addressing the burden of cardiovascular disease as early as possible. A multidisciplinary approach to the risk estimation and prevention of vascular events should be adopted at each level of health care, starting from the setting of perinatology. Recent decades have been marked with major advances in this field, with the emergence of a variety of new inflammatory and immunemediated markers of heightened cardiovascular risk in particular. The current book reflects some of the emerging concepts in cardiovascular pathophysiology and the shifting paradigm of cardiovascular risk estimation. It comprehensively covers primary and secondary preventive measures targeted at different age and gender groups. Attention is paid to inflammatory and metabolic markers of vascular damage and to the assessment of vascular function by noninvasive standardized ultrasound techniques. This is a must-read book for all health professionals and researchers tackling the issue of cardiovascular burden at individual and community level. It can also serve as a didactic source for postgraduate medical students.

\title{
How to reference
}

In order to correctly reference this scholarly work, feel free to copy and paste the following:

Heather Lee Kilty and Dawn Prentice (2012). Early Identification of Cardiovascular Risk Factors in Adolescents and Follow-Up Intervention Strategies, Cardiovascular Risk Factors, Prof. Armen Gasparyan (Ed.), ISBN: 978953-51-0240-3, InTech, Available from: http://www.intechopen.com/books/cardiovascular-risk-factors/earlyidentification-of-cardiovascular-risk-factors-in-adolescents-and-follow-up-intervention-strate

\section{INTECH}

open science | open minds

\section{InTech Europe}

University Campus STeP Ri

Slavka Krautzeka 83/A

51000 Rijeka, Croatia

Phone: +385 (51) 770447

Fax: +385 (51) 686166

www.intechopen.com

\section{InTech China}

Unit 405, Office Block, Hotel Equatorial Shanghai

No.65, Yan An Road (West), Shanghai, 200040, China 中国上海市延安西路65号上海国际贵都大饭店办公楼 405 单元

Phone: +86-21-62489820

Fax: $+86-21-62489821$ 
(C) 2012 The Author(s). Licensee IntechOpen. This is an open access article distributed under the terms of the Creative Commons Attribution 3.0 License, which permits unrestricted use, distribution, and reproduction in any medium, provided the original work is properly cited. 